\title{
GCU
}

Glasgow Caledonian

University

University for the Common Good

\section{Interventions for disorders of eye movement in patients with stroke}

Pollock, Alex; Hazelton, Christine Roberta; Henderson, Clair A.; Angilley, Jayne; Dhillon, Baljean; Langhorne, Peter; Livingstone, Katrina ; Munro, Frank A.; Orr, Heather; Rowe, Fiona J.; Shahani, Uma

Published in:

Cochrane Database of Systematic Reviews

DOI:

10.1002/14651858.CD008389.pub2

Publication date:

2011

Document Version

Publisher's PDF, also known as Version of record

Link to publication in ResearchOnline

Citation for published version (Harvard):

Pollock, A, Hazelton, CR, Henderson, CA, Angilley, J, Dhillon, B, Langhorne, P, Livingstone, K, Munro, FA, Orr, $\mathrm{H}$, Rowe, FJ \& Shahani, U 2011, 'Interventions for disorders of eye movement in patients with stroke', Cochrane Database of Systematic Reviews, vol. 2011, no. 10. https://doi.org/10.1002/14651858.CD008389.pub2

\section{General rights}

Copyright and moral rights for the publications made accessible in the public portal are retained by the authors and/or other copyright owners and it is a condition of accessing publications that users recognise and abide by the legal requirements associated with these rights.

Take down policy

If you believe that this document breaches copyright please view our takedown policy at https://edshare.gcu.ac.uk/id/eprint/5179 for details of how to contact us. 


\section{(E) Cochrane Library}

Cochrane Database of Systematic Reviews

\section{Interventions for disorders of eye movement in patients with stroke (Review)}

Pollock A, Hazelton C, Henderson CA, Angilley J, Dhillon B, Langhorne P, Livingstone K, Munro FA, Orr H, Rowe FJ, Shahani U

Pollock A, Hazelton C, Henderson CA, Angilley J, Dhillon B, Langhorne P, Livingstone K, Munro FA, Orr H, Rowe FJ, Shahani U. Interventions for disorders of eye movement in patients with stroke. Cochrane Database of Systematic Reviews 2011, Issue 10. Art. No.: CD008389.

DOI: 10.1002/14651858.CD008389.pub2.

www.cochranelibrary.com 
TABLE OF CONTENTS

HEADER . . . . . . . . . . . . . . . . . . . . . . . . . . . . . . . . . . . . 1

ABSTRACT . . . . . . . . . . . . . . . . . . . . . . . . . . . . . . . . . . . . . . . . . . . . . . .

PLAIN LANGUAGE SUMMARY . . . . . . . . . . . . . . . . . . . . . . . . . . . . . . . . . . . 2

BACKGROUND . . . . . . . . . . . . . . . . . . . . . . . . . . . . . . . . . . . . . . . . .

OBJECTIVES . . . . . . . . . . . . . . . . . . . . . . . . . . . . . . . . . . . . . . . $4 \begin{gathered}4 \\ \text { O }\end{gathered}$

METHODS . . . . . . . . . . . . . . . . . . . . . . . . . . . . . . . . . . . . . .

RESULTS . . . . . . . . . . . . . . . . . . . . . . . . . . . . . . . . . . . . . . . 9

Figure 1. . . . . . . . . . . . . . . . . . . . . . . . . . . . . . . . . . 11

DISCUSSION . . . . . . . . . . . . . . . . . . . . . . . . . . . . . . . . . . . . . 12

AUTHORS' CONCLUSIONS . . . . . . . . . . . . . . . . . . . . . . . . . . . . . . . . . . . . . .

ACKNOWLEDGEMENTS . . . . . . . . . . . . . . . . . . . . . . . . . . . . . . . . . . . 13

REFERENCES . . . . . . . . . . . . . . . . . . . . . . . . . . . . . . . . . . . . . . 14

CHARACTERISTICS OF STUDIES . . . . . . . . . . . . . . . . . . . . . . . . . . . . . . . . . . . . . .

DATA AND ANALYSES . . . . . . . . . . . . . . . . . . . . . . . . . . . . . . . . . . . . . . . . . . . . . .

ADDITIONAL TABLES . . . . . . . . . . . . . . . . . . . . . . . . . . . . . . . . . . . 21

APPENDICES . . . . . . . . . . . . . . . . . . . . . . . . . . . . . . . . . . . . . . 22

CONTRIBUTIONS OF AUTHORS . . . . . . . . . . . . . . . . . . . . . . . . . . . . . . . . . . . . . 32

DECLARATIONS OF INTEREST . . . . . . . . . . . . . . . . . . . . . . . . . . . . . . . . . 32

SOURCES OF SUPPORT . . . . . . . . . . . . . . . . . . . . . . . . . . . . . . . . . . . . . . . . . . . . .

DIFFERENCES BETWEEN PROTOCOL AND REVIEW . . . . . . . . . . . . . . . . . . . . . . . . . . . 32

INDEX TERMS . . . . . . . . . . . . . . . . . . . . . . . . . . . . . . . . . . . . . . . . . . . . . . . .

Interventions for disorders of eye movement in patients with stroke (Review)

Copyright @ 201 I The Cochrane Collaboration. Published by John Wiley \& Sons, Ltd. 


\title{
[Intervention Review]
}

\section{Interventions for disorders of eye movement in patients with stroke}

\author{
Alex Pollock ${ }^{1}$, Christine Hazelton ${ }^{1}$, Clair A Henderson ${ }^{2}$, Jayne Angilley ${ }^{3}$, Baljean Dhillon ${ }^{4}$, Peter Langhorne ${ }^{5}$, Katrina Livingstone ${ }^{6}$, \\ Frank A Munro $^{7}$, Heather Orr ${ }^{8}$, Fiona J Rowe ${ }^{9}$, Uma Shahani ${ }^{10}$ \\ ${ }^{1}$ Nursing, Midwifery and Allied Health Professions Research Unit, Glasgow Caledonian University, Glasgow, UK. ${ }^{2}$ Parliamentary, Pol- \\ icy, Press and Research, RNIB Scotland, Edinburgh, UK. ${ }^{3}$ Cornwall \& Isles of Scilly Primary Care Trust, Newquay, UK. ${ }^{4}$ Department \\ of Ophthalmology, Clinical and Surgical Sciences, NHS Lothian, Edinburgh, UK. ${ }^{5}$ Academic Section of Geriatric Medicine, University \\ of Glasgow, Glasgow, UK. ${ }^{6}$ Community Stroke Team - South Glasgow, NHS Greater Glasgow and Clyde, Glasgow, UK. ${ }^{7}$ S/E Com- \\ munity Optometrist, Frank Munro Optometrists, Glasgow, UK. ${ }^{8}$ Stroke Rehabilitation Unit, NHS Tayside, Brechin, UK. ${ }^{9}$ Directorate \\ of Orthoptics and Vision Science, University of Liverpool, Liverpool, UK. ${ }^{10}$ Department of Visual Sciences, Glasgow Caledonian \\ University, Glasgow, UK
}

Contact address: Alex Pollock, Nursing, Midwifery and Allied Health Professions Research Unit, Glasgow Caledonian University, Buchanan House, Cowcaddens Road, Glasgow, G4 0BA, UK. alex.pollock@gcu.ac.uk.

Editorial group: Cochrane Stroke Group.

Publication status and date: New, published in Issue 10, 2011.

Review content assessed as up-to-date: 1 June 2011.

Citation: Pollock A, Hazelton C, Henderson CA, Angilley J, Dhillon B, Langhorne P, Livingstone K, Munro FA, Orr H, Rowe FJ, Shahani U. Interventions for disorders of eye movement in patients with stroke. Cochrane Database of Systematic Reviews 2011, Issue 10. Art. No.: CD008389. DOI: 10.1002/14651858.CD008389.pub2.

Copyright (C) 2011 The Cochrane Collaboration. Published by John Wiley \& Sons, Ltd.

\begin{abstract}
A B S T R A C T
Background

Eye movement disorders may affect over $70 \%$ of stroke patients. These eye movement disorders can result in difficulty maintaining the normal ocular position and difficulty moving the eyes appropriately. The resulting functional disabilities include a loss of depth perception, reduced hand-to-eye co-ordination, marked difficulties with near tasks and reading and reduced ability to scan the visual environment. They can also impact on the effectiveness of rehabilitation therapy. There are a wide variety of different treatment interventions proposed for eye movement disorders after stroke. However, in the past, there has been a lack of evidence specific to the impact of interventions on the functional outcome of patients with stroke.
\end{abstract}

Objectives

To determine the effects of interventions for eye movement disorders on functional ability following stroke.

\section{Search methods}

We searched the Cochrane Stroke Group Trials Register (February 2011), the Cochrane Eyes and Vision Group Trials Register (December 2009) and nine electronic bibliographic databases including CENTRAL (The Cochrane Library 2009, Issue 4), MEDLINE (1950 to December 2009), EMBASE (1980 to December 2009), CINAHL (1982 to December 2009), AMED (1985 to December 2009), and PsycINFO (1967 to December 2009). We also searched reference lists and trials registers, handsearched journals and conference proceedings, and contacted experts.

Interventions for disorders of eye movement in patients with stroke (Review)

Copyright @ 201 I The Cochrane Collaboration. Published by John Wiley \& Sons, Ltd. 


\section{Selection criteria}

Randomised trials in adults after stroke where the intervention was specifically targeted at improving the eye movement disorder or improving the ability of the participant to cope with the eye movement disorder. The primary outcome was functional ability in activities of daily living. Secondary outcomes included functional ability in extended activities of daily living, eye movement measures, balance, falls, depression or anxiety, discharge destination or residence after stroke, quality of life and social isolation, adverse events, and death.

\section{Data collection and analysis}

Two authors independently screened abstracts, extracted data and appraised trials. We undertook assessment of methodological quality for allocation concealment, blinding of outcome assessor, method of dealing with missing data, and other potential sources of bias.

\section{Main results}

Two studies (28 participants but only five were people with stroke) met the inclusion criteria and were included in this review. Both studies investigated pharmacological interventions for disorders of eye movement in patients with stroke. It was not appropriate to pool data and we were not able to draw conclusions from these studies. We found no other randomised studies which investigated interventions for disorders of eye movement in patients with stroke.

\section{Authors' conclusions}

There is insufficient evidence to reach conclusions about the effectiveness of interventions for patients with eye movement disorders after stroke. High quality research in the form of well-designed randomised trials are urgently required.

\section{PLAIN LANGUAGE S MMARY}

\section{Interventions for eye movement disorders in people with stroke}

Eye movement disorders may affect over $70 \%$ of stroke patients and can make it difficult to keep both eyes in their normal position when looking straight ahead, or can make it difficult to move the eyes accurately to look in a different direction. This can affect patients' perception of depth, makes it difficult for them to take in their whole surroundings and can severely affect the ability to read. We found only two randomised controlled trials which investigated treatments for eye movement disorders. Both of these studies investigated the effect of drug treatments. A total of 28 participants were included but only five of these were people with stroke. One study found that the people with stroke responded differently to the drug treatment than people who had eye movement disorders due to other conditions. These studies provide too little evidence from which to reach any conclusions about the effectiveness of interventions for patients with eye movement disorders after stroke. Further research is urgently required.

\section{B A C K G R O U N D}

The association between visual impairment and disability in activities of daily living is well established (Wolter 2006). The services available to patients with visual problems following stroke are inconsistent at present. We aim to provide an evidence base to facilitate the development of further research and promote best treatments for patients with visual problems following stroke.

This review is one of a series of reviews being supported by the Royal National Institute for the Blind (RNIB). The aim of these reviews is to identify the evidence base for treatments of visual problems following stroke. The project team aims to develop appropriate primary research proposals on completion of these reviews.

\section{Description of the condition}

Disorders of eye movements are caused by damage to the extraocular muscle, the cranial nerves supplying the ocular muscles, or to the neural pathways that control these nerves. It has been reported that in symptomatic patients up to $86 \%$ of those with 
stroke or non-traumatic acquired brain injury have eye movement disorders (Ciuffreda 2007; Rowe 2009a) and in a general population of stroke patients, at various stages of recovery, between $7 \%$ and 55\% have eye movement disorders (Clisby 1995; Freeman 1987; MacIntosh 2003). These disorders can cause a variety of problems (Jones 2006; Pederson 1981; Rowe 2009a) including the following difficulties and eye movements.

\section{Difficulties in maintaining the normal ocular position}

- Conjugate eye deviation: both eyes turn constantly to one side.

- Strabismus: one eye deviates horizontally or vertically, or both, with or without the eye rotating away from the straight position so the eyes are no longer aligned.

- Nystagmus: frequent involuntary oscillations and other random eye movements.

\section{Difficulty with moving eyes appropriately}

- Saccades: fast movements that carry the eye from one target to another.

- Pursuits: slow movements that allow a moving object to be followed.

- Fixation: ability to maintain steady eye position on a target.

- Convergence: ability of the eyes to turn in to focus on near objects.

- Divergence: ability of the eyes to turn out and focus on distant objects.

- Vestibulo-ocular reflex: movement of the eyes in response to a quick head movement.

- Palsy: inability to use one or more of the muscles that move the eye up, down, left or right.

The result is a range of functional disabilities. These include a loss of depth perception, reduced hand-to-eye co-ordination and marked difficulties with near tasks and reading (MacIntosh 2003). Reduced ability to scan the visual environment may affect visual memory, recognition, the ability to formulate plans and decision making (Wolter 2006). The disorders may also impact on the effectiveness of rehabilitation therapy in regaining mobility and activities of daily living (MacIntosh 2003), and have an impact on quality of life (Ciuffreda 2008).

\section{Description of the intervention}

There are a number of different treatment and management approaches available to patients with eye movement disorders. This review considers any intervention that is specifically targeted at improving the disorder, or improving the ability of the patient to cope with it.

Treatments for eye movement disorders can be described as restitution, compensation or substitution (Kerkhoff 2000). In addition to these types of treatments, this review will also consider assessment and screening interventions that are specifically targeted at patients with eye movement disorders.

These interventions may include, but not be limited to, the following.

- Restitutive interventions: convergence training, pursuit training, saccade training.

- Compensative interventions: training eye movements for reading, compensatory head posture or movements, use of eye blinks or colour cues, training in activities of daily living.

- Substitutive interventions: prisms, eye patches, injections and surgery, magnification, environmental modification.

- Assessment and screening interventions: standardised visual assessment, screening and referral for visual assessment and intervention, assessment of different types of eye movement.

\section{How the intervention might work}

\section{Restitution}

Restitution includes the biochemical events that help restore functional neural tissue: the reduction of oedema, absorption of blood, restoration of normal neuronal physiology and restoration of axon transport. In the past it has been thought that restitutive approaches would have limited effect in visual rehabilitation. However, treatments of convergent fusion and stereopsis through repetition training of the deficient function have been reported as effective (Kerkhoff 2000). Restitutive interventions include those where there is direct training of the impaired function or repetitive stimulation of eye movement.

\section{Compensation}

Compensation aims to improve the mismatch between the patients' skills and the demands placed on them by their environment by teaching them to compensate using a spared or intact function (Kerkhoff 1999; Kerkhoff 2000).

\section{Substitution}

Substitution involves adaptation of visual components that have been lost or disrupted through the use of optic devices or environmental modifications (Kerkhoff 1999; Kerkhoff 2000).

\section{Assessment and screening interventions}

These may work by ensuring that the eye movement disorder is appropriately diagnosed, which enables other interventions to be prescribed or enables patients to be given advice and education about the management of their condition and adaptation of their environment. 
The interventions for eye movement disorders are therefore proposed to work by either restoring the eye movement (restitution); compensating for the eye movement disorder by changing behaviour or activity (compensation); substituting for the eye movement disorder by using a device or extraneous modification (substitution); or ensuring appropriate diagnosis, referral and treatment prescription through standardised assessment or screening, or both.

\section{Why it is important to do this review}

Eye movement disorders are relatively common after stroke. They can result in wide-ranging functional difficulties (Rowe 2009a; Rowe 2009b) and may negatively impact on rehabilitation after stroke. There are a wide variety of different treatment interventions proposed for eye movement disorders after stroke. The body of evidence relating to eye movement disorders is growing. However, in the past, there has been a lack of evidence specific to the impact of interventions on the functional outcome of patients with stroke (Ciuffreda 2008). There are two recent published reviews of the literature relating to visual problems following stroke (Jones 2006; Wolter 2006). Both of these reviews provide a broad overview of the literature relating to visual problems after stroke but do not provide a rigorous, systematic analysis of outcomes of treatment interventions for eye movement disorders. Two reviews (Barrett 2009; Riggs 2007) were completed but with a number of methodological limitations. Neither review identified primary evidence relating to eye movement disorders in patients with stroke. A high-quality systematic review of the existing evidence base is essential in order to determine the evidence for the effectiveness of any treatment or management approaches for stroke patients with eye movement disorders. This review will also facilitate appropriate planning and prioritisation of future primary research.

\section{O B J E C T IVES}

\section{Research question}

Do interventions for eye movement disorders improve functional ability following stroke?

\section{Specific objectives}

1. To determine whether, in patients with eye movement disorders following stroke:

i) restitutive interventions are more effective than control, placebo or no intervention at improving functional ability in activities of daily living; ii) compensative interventions are more effective than control, placebo or no intervention at improving functional ability in activities of daily living;

iii) substitutive interventions are more effective than control, placebo or no intervention at improving functional ability in activities of daily living;

iv) assessment and screening interventions are more effective than standard care at improving functional ability in activities of daily living.

2. To determine whether, in patients with eye movement disorders following stroke:

i) restitutive interventions are more effective than control, placebo or no intervention at improving secondary outcomes;

ii) compensative interventions are more effective than control, placebo or no intervention at improving secondary outcomes;

iii) substitutive interventions are more effective than control, placebo or no intervention at improving secondary outcomes;

iv) assessment and screening interventions are more effective than standard care at improving secondary outcomes.

3. To explore the relationship between patient characteristics and the effect of interventions aimed at improving functional abilities in activities of daily living by using subgroup analysis.

4. To make specific recommendations for future research into the effectiveness of interventions for eye movement disorders based on a knowledge of the existing evidence base.

\section{METHOD S}

\section{Criteria for considering studies for this review}

\section{Types of studies}

Randomised controlled trials (RCTs) and randomised controlled cross-over trials (analysing the first phase as a parallel group trial).

\section{Types of participants}

Adult participants (over 18 years of age) after stroke (using the World Health Organization (WHO) definition of stroke, or a clinical definition if not specifically stated, that is, signs and symptoms persisted longer than 24 hours) and with a clinical diagnosis of an eye movement disorder. The eye movement disorder must have occurred as a direct result of the stroke. We accepted studies that included participants based on symptoms which can be assumed to be present as a direct result of an eye movement disorder. 
These symptoms include double vision, difficulty reading, blurred vision, wobbling vision, and excessive head movements.

We documented the type of eye movement disorder and planned to conduct subgroup analysis to investigate the effect of each type. If possible, we documented the type of eye movement disorder (III, IV, and VI nerve palsy; reduced fixation or gaze holding; saccadic palsy or problems; smooth pursuit palsy or problems; strabismus; nystagmus; reduced convergence; conjugate deviation; skew deviation), the deviation of eye movement (horizontal, vertical, torsional), and the severity of eye movement disorder (slight, small, moderate, marked; paralysis or paresis; monocular or binocular) and planned to investigate the effects via further subgroup analyses.

\section{Types of interventions}

We included any intervention that was specifically targeted at improving the defects of eye movement or improving the ability of the patient to cope with the disorder. We planned to classify interventions as either restitution, compensation, substitution, or assessment and screening.

We compared interventions with a no treatment, placebo or a control intervention, or against standard care. We planned four specific comparisons: (1) restitutive interventions versus no treatment, placebo or control; (2) compensative interventions versus no treatment, placebo or control; (3) substitutive interventions versus no treatment, placebo or control; and (4) assessment and screening interventions versus standard care. We identified an additional comparison following the selection of included trials: (5) pharmacological interventions versus no treatment, placebo or control. We documented a description of the placebo or control intervention, or standard care. We accept as standard care any 'normal', 'routine' or 'usual' care as defined by the researchers.

\section{Types of outcome measures}

If possible, we assessed the outcome at the end of the intervention period and at a follow-up point (ideally six months after the completion of the intervention).

\section{Primary outcomes}

\section{Functional ability in activities of daily living}

We included studies using the following validated scales: Barthel Activities of Daily Living Index (Mahoney 1965), Functional Independence Measure (FIM) (Smith 1990), Modified Rankin Scale, Katz Index of Activities of Daily Living (Katz 1963), and the Rehabilitation Activities Profile. If a study reported more than one of these functional ability scales, we used the scale listed earliest in this list.

\section{Secondary outcomes}

Functional ability in extended activities of daily living

Nottingham Extended Activities of Daily Living scale, Lawton Instrumental Activities of Daily Living, Frenchay Activities Index (Holbrook 1983), Rivermead ADL score.

\section{Eye movement}

From orthoptic tests, including size of deviation, gradation of movements, severity of disorder (slight, small, moderate, marked; paralysis or paresis; monocular or binocular).

\section{Balance}

Berg Balance Scale (Berg 1989), Functional Reach (Duncan 1990), Get Up and Go Test (Mathias 1986), Standing Balance Test, Step Test or other standardised balance measure. We did not include measures of weight distribution or postural sway during standing as it was not possible for us to establish the relationship between the ability to maintain balance and these outcomes.

\section{Falls}

Number of reported falls, Falls Efficacy Scale (Tinetti 1990).

\section{Depression and anxiety}

Hospital Anxiety and Depression Scale, Beck Depressive Inventory, General Health Questionnaire, Geriatric Depression Scale.

\section{Discharge destination or residence after stroke}

Dichotomous variable: discharged to previous place of residence (that is, place of residence prior to stroke) or discharged to alternative destination.

\section{Quality of life and social isolation}

EQ5D, Health-Related Quality of Life Scale, Quality of WellBeing Scale, Short Form 36.

\section{Adverse events}

Any reported adverse events, excluding falls and death.

\section{Death}

\section{Search methods for identification of studies}

See the 'Specialised register' section in the Cochrane Stroke Group module. 


\section{Electronic searches}

We searched the Cochrane Stroke Group Trials Register (February 2011), the Cochrane Eyes and Vision Group Trials Register (December 2009), and the following electronic bibliographic databases:

- Cochrane Central Register of Controlled Trials (CENTRAL) (The Cochrane Library 2009, Issue 3 at www.thecochranelibrary.com (Appendix 1);

- MEDLINE (1950 to December 2009) (Appendix 2);

- EMBASE (1980 to December 2009) (Appendix 3);

- CINAHL (1982 toDecember 2009) (Appendix 4);

- AMED (1985 to December 2009) (Appendix 5);

- PsycINFO (1967 to December 2009) (Appendix 6);

- Dissertations \& Theses (PQDT) database (1861 to

December 2009);

- British Nursing Index (1985 to December 2009);

- PsycBITE (Psychological Database for Brain Impairment

Treatment Efficacy) at www.psycbite.com (December 2009).

\section{Searching other resources}

In an effort to identify further published, unpublished and ongoing trials, we undertook the following.

1. Searched the following registers of ongoing trials: 2010);

i) ClinicalTrials.gov (http://clinicaltrials.gov/); (February

ii) Current Controlled Trials (www.controlled-trials.com)

(February 2010);

iii) Trials Central (www.trialscentral.org) (February 2010);

iv) Stroke Trials Registry (www.strokecenter.org/trials/)

(February 2010);

v) Health Service Research Projects in Progress ( wwwcf.nlm.nih.gov/hsr_project/home_proj.cfm) (February 2010);

vi) National Eye Institute Clinical Studies Database ( http://clinicalstudies.info.nih.gov/cgi/protinstitute.cgi? NEI.0.html) (February 2010).

2. Handsearched the following journals and conference proceedings:

i) British Orthoptic Journal (1939 to 2003);

ii) British and Irish Orthoptic Journal (2004 to 2010);

iii) Australian Orthoptic Journal (1959 to 2010);

iv) Proceedings of the European Strabismological Association (ESA) (1969 to 2009);

v) International Strabismological Association (ISA)

(1966 to 2010);

vi) International Orthoptic Association (IOA) ( www.liverpool.ac.uk/orthoptics/research/search.htm) (1967 to 2008);

vii) Proceedings of Association for Research in Vision and Ophthalmology (www.arvo.org) (1969 to 2010).
3. Searched the references supplied by commercial companies providing interventions aimed at restoration of eye movements.

4. Performed citation tracking using Web of Science Cited Reference Search for all included studies.

5. Searched the reference lists of included trials and review articles about vision after stroke.

6. Contacted experts in the field (including authors of included trials and excluded studies identified as possible preliminary or pilot work).

We searched for trials in all languages and arranged for translation of trials published in languages other than English.

\section{Data collection and analysis}

One review author $(\mathrm{CH})$ ran all the electronic searches, downloaded references into bibliographic software, and removed duplicates. One review author $(\mathrm{CH})$ excluded any titles which were obviously not related to stroke and vision. We obtained the abstracts for any references related to stroke and vision. Two review authors $(\mathrm{CH}, \mathrm{AP})$ independently considered each of these abstracts, excluded any studies which were clearly not RCTs or cross-over trials, and excluded any studies where the intervention was not specifically aimed at improving the eye movement disorder or the patient's ability to cope with the eye movement disorder. We resolved any disagreements through discussion. We obtained the full papers for any studies included at this stage.

\section{Selection of studies}

Two review authors $(\mathrm{CH}, \mathrm{AP})$ independently applied the selection criteria, considering and documenting the type of studies, type of participants, intervention, comparison intervention, and the outcome measures. Each review author classified each study as include or exclude. If there was disagreement between these two review authors, they reached consensus through discussion involving a third review author.

We listed any excluded studies that included participants with eye movement disorders in the Characteristics of excluded studies table, with the reason for exclusion. We did not list in the Characteristics of excluded studies table studies that were excluded because they included participants that did not have eye movement disorders (that is, visual neglect, age-related visual problems, or visual field loss) unless the two review authors agreed that there was a clear reason to do so.

\section{Data extraction and management}

We used a pre-designed data extraction form to record data from the included studies. Two review authors $(\mathrm{CH}, \mathrm{AP})$ independently documented the following.

- Methods: study design, method of randomisation.

Interventions for disorders of eye movement in patients with stroke (Review)

Copyright @ 201 I The Cochrane Collaboration. Published by John Wiley \& Sons, Ltd. 
- Participants: number of participants, inclusion criteria. We documented the method of diagnosing the eye movement disorder. We recorded the country of origin of participants.

- Interventions: description of interventions given to each treatment group including, if relevant, the duration, intensity, frequency, or dose. We classified the type of intervention as restitution, compensation, substitution, or assessment and screening, and the type of control as no treatment, placebo, control, or standard care. We documented the professional background of the person providing the intervention (e.g. occupational therapist, orthoptist).

- Outcomes: we documented the primary and secondary outcomes relevant to this review. If a study used a number of different methods of measuring the same outcome, we noted the outcome to be used for any subsequent analysis.

- Notes: we recorded any important confounding variables. If a study included more than two intervention groups, we also recorded the method of including these groups in any subsequent analysis.

In addition, the review authors independently documented, if data allowed, the following demographics of the included participants: age, gender, place of residence, type of stroke, side of stroke, time since stroke, initial eye movement disorders, and initial functional ability.

If there were any discrepancies between data extracted by the two review authors, these were resolved through discussion.

\section{Assessment of risk of bias in included studies}

We assessed risk of bias by answering the following questions for each included study, and documenting this within the 'Risk of bias' tables.

\section{Was allocation adequately concealed?}

Studies with adequate concealment included those which used central randomisation at a site remote from the study, computerised allocation in which records were in a locked readable file accessible only after entering patient details, or the drawing of opaque envelopes. Studies with inadequate concealment included those using an open list or a table of random numbers, open computer systems, or the drawing of non-opaque envelopes. Studies with unclear concealment included those with no or inadequate information in the report.

\section{Was knowledge of the allocated intervention adequately concealed from the outcome assessor?}

We considered studies to be adequately concealed if the outcome assessor was masked and the report did not identify any unmasking. We considered studies inadequately concealed if the outcome assessor was not masked or where the report clearly identified that unmasking occurred during the study. We documented concealment as unclear if a study did not state whether or not an outcome assessor was masked or there was insufficient information to judge.

\section{Were incomplete outcome data adequately addressed?}

Studies that adequately addressed incomplete outcome data had: no missing outcome data; missing outcome data which were unlikely to be related to a true outcome; missing outcome data which were balanced in numbers across intervention groups, with similar reasons for missing data across the groups; a reported effect size (difference in means or standardised difference in means) among missing outcomes which were not enough to have a clinically relevant impact on observed effect size; or missing data which had been imputed using appropriate methods. Studies which inadequately addressed incomplete outcome data had: missing outcome data which were likely to be related to a true outcome, with either an imbalance in numbers or reasons for missing data across intervention groups; a reported effect size (difference in means or standardised difference in means) among missing outcomes enough to induce clinically relevant bias in observed effect size; or as-treated analysis done with substantial departure of the intervention received from that assigned at randomisation. We documented the addressing of incomplete outcome data as unclear if there was insufficient reporting to allow this to be assessed, or if this was not addressed in the report.

\section{Was the study apparently free of other problems that could} put it at a high risk of bias?

We assessed a study not to be free of bias if it was assessed to have at least one important risk of bias, such as a potential source of bias related to the specific study design used; an extreme baseline imbalance; a claim to have been fraudulent; or some other problem. If there was insufficient information, or the information provided was unclear, we documented the risk of other bias as unclear.

We produced a 'Risk of bias' summary figure to illustrate the potential biases within each of the included studies.

\section{Measures of treatment effect}

We planned to use Review Manager 5 (RevMan 2011) to carry out statistical analyses to determine the treatment effect of:

1. restitutive interventions (compared with no treatment, control, placebo, or standard care);

2. compensative interventions (compared with no treatment, control, placebo, or standard care);

3. substitutive interventions (compared with no treatment, control, placebo, or standard care);

4. assessment and screening interventions (compared with standard care). 
We planned to use a random-effects model for all statistical analyses. For dichotomous variables we planned to calculate the treatment effect using a fixed-effect model and report it as a Peto odds ratio (OR) with $95 \%$ confidence interval (CI). For continuous data we planned to calculate the treatment effect using standardised mean differences (SMD) and 95\% CI where different studies used different scales for the assessment of the same outcome, and using mean differences (MD) and 95\% CI where studies all used the same method of measuring the outcome.

\section{Unit of analysis issues}

The primary outcome of functional ability in activities of daily living and secondary outcomes of functional ability in extended activities of daily living, eye movement data, balance, falls, depression and anxiety, and quality of life and social isolation comprise either ordinal data from measurement scales, count data, or continuous data. We planned to analyse these as continuous variables. If reported outcomes had a scale where a lower value is indicative of a better outcome (for example, a count of the number of falls, depression and anxiety scales), we multiplied the reported values by -1 so that in all analyses a higher value would be indicative of a better outcome.

If studies reported change values these would be included with follow-up values in the meta-analysis, but we planned sensitivity analyses to investigate the effect of including these data.

We planned to analyse discharge destination, adverse events, and death as dichotomous variables.

\section{Dealing with missing data}

If an included study did not report a particular outcome, we would not include that study in the analyses of that outcome.

If an included study had missing data (for example, it reported the mean but not standard deviations for the follow-up data) we would take logical steps to enter an assumed value. Such steps might include estimating a standard deviation based on a reported standard error, or estimating a follow-up standard deviation based on a baseline value. We planned to do sensitivity analyses to investigate the effect of entering assumed values.

\section{Assessment of heterogeneity}

We planned to determine heterogeneity using the $\mathrm{I}^{2}$ statistic. We would consider $\mathrm{I}^{2}>50 \%$ as substantial heterogeneity. If $\mathrm{I}^{2}$ was less than or equal to $50 \%$ we would use a fixed-effect meta-analysis. If $\mathrm{I}^{2}$ was greater than $50 \%$, we would explore the individual trial characteristics to identify potential sources of heterogeneity, using pre-planned subgroup analyses.

\section{Assessment of reporting biases}

We attempted to avoid reporting biases by using a comprehensive search strategy that included searching for unpublished studies and searching trials registers. We planned to carry out sensitivity analyses to explore the effect of publication type.

\section{Data synthesis}

Two review authors $(\mathrm{CH}, \mathrm{AP})$ independently extracted data from the included trials. One review author $(\mathrm{CH})$ entered the data into RevMan 5 (RevMan 2011) and the other review author (AP) checked the entries. They resolved any disagreements through discussion, with reference to the original report.

\section{Subgroup analysis and investigation of heterogeneity}

We intended to explore heterogeneity by subgroup analyses to investigate the effect of:

- age (under 60 years, 60 years and over);

- gender (male, female);

- time after stroke (less than three months, less than six months, more than six months, at entry to study);

- type of eye movement disorder (III, IV, VI nerve palsy; reduced fixation or gaze holding; saccadic palsy or problems; smooth pursuit palsy or problems; strabismus; nystagmus; reduced convergence; conjugate deviation; skew deviation);

- deviation of eye movement (horizontal, vertical, torsional);

- severity of eye movement disorder (slight, small, moderate, marked; paralysis and paresis; monocular and binocular);

- side of stroke (left, right);

- presence of age-related visual problems (presence, absence);

- presence of visual field impairment (presence, absence);

- presence of visual inattention (presence, absence);

- level of motor impairment (mild, moderate, severe);

- level of cognitive impairment (mild, moderate, severe);

- type of treatment (e.g. for compensative interventions: saccadic eye movement, activities of daily living training; for substitutive interventions: prisms, patches, environmental modifications; for assessment and screening: by orthoptist, occupational therapist, doctor).

We planned to use an established method for subgroup analyses (Deeks 2001). Prior to future updates of this review we will debate and reach consensus on the importance of these subgroup analyses, and we will consider reducing the number of planned subgroup analyses. For future updates we will carry out the planned subgroup analyses when there are six or more studies included in a single analysis, all with sufficient information to determine the subgroups. 


\section{Sensitivity analysis}

We intended to carry out sensitivity analysis to explore the effect of the following methodological features.

- Allocation concealment: we planned to re-analyse data excluding trials with inadequate or unclear allocation concealment.

- Masking of outcome assessor: we planned to re-analyse data excluding trials without or with unclear masking of outcome assessor.

- Missing outcome data: we planned to re-analyse data excluding trials with inadequate or unclear methods of dealing with missing outcome data.

- Other bias: we planned to re-analyse data excluding trials assessed to have other bias or were unclear as to whether they had other bias.

- Publication type (peer-reviewed journal, conference abstract or proceedings, doctoral dissertation): we planned to re-analyse data including only those trials from peer-reviewed journals.

\section{RES U L T S}

\section{Description of studies}

See: Characteristics of included studies; Characteristics of excluded studies; Characteristics of ongoing studies; Characteristics of studies awaiting classification.

\section{Results of the search}

Our search strategy identified 7357 titles in the main databases. After elimination of duplicates and obviously irrelevant studies we were left with 1034 'possibly relevant' abstracts that covered all topics in this series of reviews: 373 related to visual field loss and disorders of eye movement. We obtained these 373 abstracts and two review authors ( $\mathrm{CC}$ and $\mathrm{CH}$ ) initially evaluated their inclusion according to the criteria described in the protocol. Where disagreement arose they sought the opinion of a third review author (AP). We assessed 81 abstracts as 'include' or 'unsure' for the visual field and eye movement disorders review and we obtained the full papers for these studies. Review by AP and $\mathrm{CH}$ of the full papers led to the inclusion in this review of two of these 81 studies. One of the 81 studies had inadequate information on the inclusion criteria and randomisation methods to classify it; contact with the authors has so far been unsuccessful. It has been added to the Characteristics of studies awaiting classification table. Where disagreements or uncertainties arose, we held consensus discussions involving additional authors where required.

One review author $(\mathrm{CH})$ conducted the wider search strategy, which involved databases of trials, commercial websites, hand- searching and cited reference searches. The final decision regarding inclusion of prospective studies was decided by discussion $(\mathrm{CH}$ and $\mathrm{AP})$. We did not identify any further trials that could be included in the review; however, we identified one ongoing trial via www.clinicaltrials.gov. Two trials had to be investigated further, from www.clinicaltrials.gov and from the Cochrane Central Register of Controlled Trials (CENTRAL). Of these two trials, one was found to be ineligible and the other requires further clarification before a decision can be made. Their details are in the Characteristics of excluded studies table and Characteristics of studies awaiting classification table, respectively.

Thus we identified a total of two studies for inclusion (Leigh 1991; Strupp 2003). In addition, we identified one ongoing study (Rosner 2010) and two studies which are awaiting assessment ( Hofferberth 1995; Muchnick 1998).

\section{Included studies}

Two studies (28 randomised participants, five of whom were participants with stroke) met the inclusion criteria for this review (Leigh 1991; Strupp 2003). Full descriptions of the studies can be found in the Characteristics of included studies table and in Table 1 (settings of included studies), Table 2 (demographics of included participants), and Table 3 (disorders of eye movements). A brief overview of the studies is presented below.

\section{Study design}

Both studies were randomised cross-over trials (Leigh 1991; Strupp 2003). Both studies provided information on the procedures for randomisation and allocation concealment.

\section{Interventions studied}

The interventions studied by both included trials were systemic pharmacological interventions: Leigh 1991 compared trihexyphenidyl ( $5 \mathrm{mg}$ capsules) with tridihexethyl chloride $(25 \mathrm{mg}$ capsules); Strupp 2003 compared $20 \mathrm{mg}$ 3,4 diaminopyridine (DAP) plus lactose capsules with lactose-only capsules.

We had not anticipated identifying trials of pharmacological interventions for eye movement disorders. Systemic pharmacological interventions were not, therefore, included within the classification of interventions (as restitution, compensation, substitution or assessment and screening interventions) proposed in the protocol. Following the protocol, review authors $(\mathrm{CH}, \mathrm{AP})$ independently attempted to categorise the systemic pharmacological interventions using the proposed classification system. Disagreement between these review authors led to a consensus discussion involving a further three expert reviewers (PL, BD, FR). Consensus could not be reached regarding the classification of the systemic pharmacological interventions using the protocol classification and it was agreed that an additional classification, pharmacological interventions, should be introduced. 


\section{Pharmacological interventions}

Both studies investigated the effects of pharmacological interventions. In both of these studies the intervention was systemic drug treatment for nystagmus. One of the studies (Strupp 2003) compared the effect of a drug with a placebo intervention. The other (Leigh 1991) planned to compare the effect of the drug with a placebo. However, the planned placebo intervention was found to have an active effect on the outcomes measured, so this study was considered to compare the effect of two different pharmacological interventions.

\section{Restitutive, compensative, or substitutive interventions}

We found no trials investigating the effectiveness of restitutive, compensative or substitutive interventions.

\section{Assessment and screening interventions}

We found no trials investigating the effectiveness of assessment and screening interventions on relevant outcomes.

\section{Studies included in comparisons within this review}

One study (Strupp 2003) compared an active treatment with a control or placebo treatment. This study included only three participants whose eye movement disorder was caused by a stroke. The results from these patients were reported to be different from the other patients, which suggests that the response to the intervention in stroke patients may be different to the response of people with nystagmus not related to stroke. We chose not to include these data in a formal comparison as presentation of the results from this small group could prove misleading.

\section{Populations studied}

Both of the studies (Leigh 1991; Strupp 2003) included participants with nystagmus caused by mixed aetiologies including cerebellar atrophy, multiple sclerosis and post-surgical hypoxia. The percentage of stroke patients was: Leigh 1991, 20\%; and Strupp 2003, 18\%. Neither study noted the co-existance of any age-related eye problems, cognitive or motor problems. Both studies excluded participants with visual inattention, and Leigh 1991 also excluded participants with visual field loss.

\section{Sample size}

The sample sizes were two and three stroke patients in Leigh 1991 and Strupp 2003 respectively.

\section{Outcome measures}

\section{Primary outcome}

- Functional ability in activities of daily living. Neither of the included studies used a measure of functional ability.

\section{Secondary outcomes}

- Eye movement. Both trials measured aspects of the eye movements. Strupp 2003 used two-dimensional videooculography to record eye movements in horizontal and vertical directions. Leigh 1991 used the magnetic search coil technique to measure horizontal and vertical rotations, and an Amsler grid and video recording to measure eye movement during attempted fixation in the primary position and at 10 degrees horizontally and vertically.

- Adverse events. Strupp 2003 assessed adverse events by asking participants if they experienced side-effects 30 and 60 minutes after the intervention was administered.

\section{Excluded studies}

Reasons for the exclusion of studies that were initially thought to be relevant are provided in the table of Characteristics of excluded studies. We excluded one study (Repka 1989) because communication with the study author identified that patients with stroke were excluded from the study.

\section{Risk of bias in included studies}

Assessment of risk of bias for individual studies is described in the risk of bias tables in Characteristics of included studies and summarised in Figure 1. 
Figure I. Risk of bias summary: review authors' judgements about each risk of bias item for each included study.

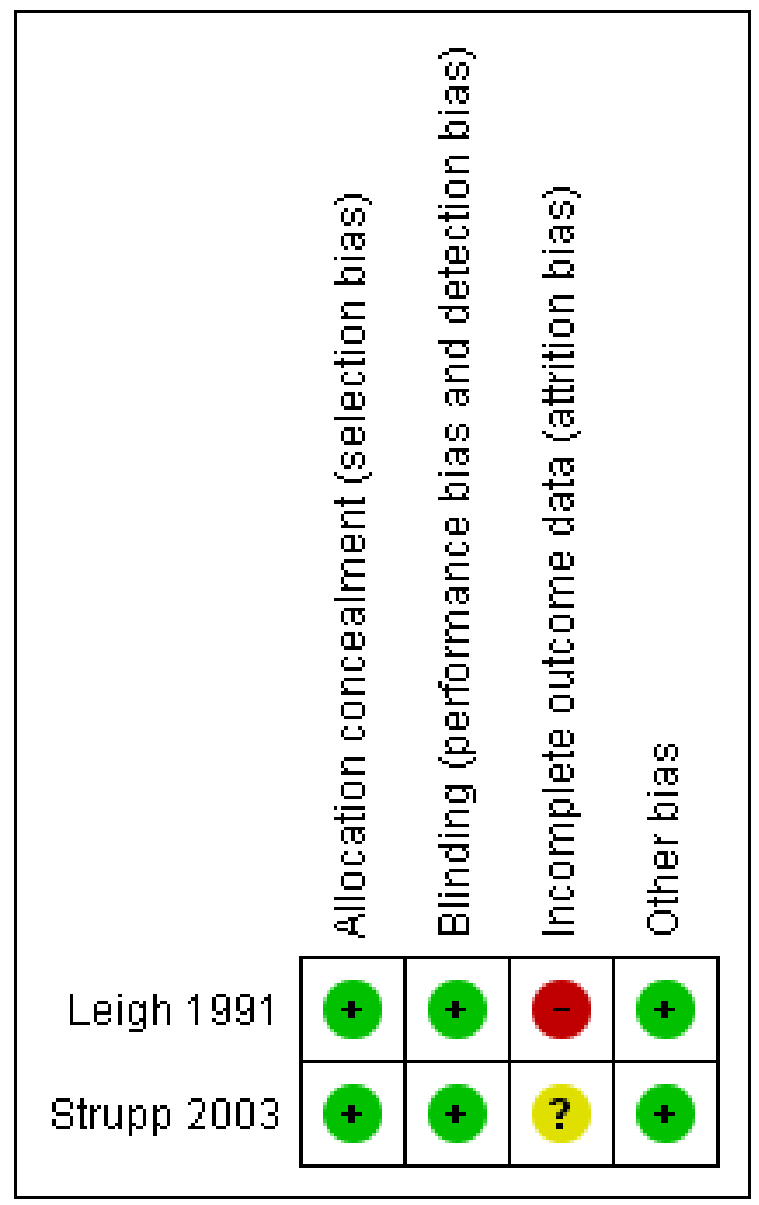

\section{Allocation}

Both studies were described as randomised double-blind cross-over trials and were assessed to have adequate allocation concealment.

\section{Blinding}

Both studies described that the drugs administered to both treatment groups were identical to look at. Strupp 2003 stated that masking was maintained until after data analysis was complete. Leigh 1991 did not give specific information about masking. However, since the interventions were administered as identical looking drugs, the review authors assumed that participants and outcome assessors were adequately masked to the intervention. Both studies were, therefore, assessed to have adequate blinding.

Incomplete outcome data
A number of participants dropped out of Leigh 1991 for a variety of reasons, including adverse events, leading the review authors assessment that this could be a potential source of bias. One participant was excluded from Strupp 2003; the review authors were uncertain of the impact of this and judged the risk of bias to be uncertain.

\section{Other potential sources of bias}

We judged both Leigh 1991 and Strupp 2003 unlikely to be at risk of other potential sources of bias. This assessment was based on an absence of information suggesting bias rather than the presence of information indicating that the studies were free of bias.

\section{Effects of interventions}




\section{Pharmacological interventions}

We found insufficient evidence and data to carry out any analyses to explore the effect of pharmacological interventions compared with control or placebo interventions (see Included studies for details).

Leigh 1991 reported a study that was designed as a placebo controlled trial comparing the anti-cholinergic 'active' drug trihexyphenidyl with the 'placebo' drug tridihexethyl chloride, which does not cross the blood-brain barrier. The authors report, based on pooled data from a cross-over study, that trihexyphenidyl was generally not effective in reducing the velocity of nystagmus. Trihexethyl chloride did have an effect, reducing nystagmus velocity in four out of six participants, but was associated with side-effects. Strupp 2003 reported that 3,4-diaminopyridine, a potassium channel blocker, had a significant effect on nystagmus velocity compared with a placebo (of lactose). However, this result was not found in the subgroup of stroke patients.

\section{DISCUSSION}

\section{Summary of main results}

We found two studies which both investigated pharmacological interventions for disorders of eye movement in patients with stroke. The total number of included stroke patients was five. It was not appropriate to pool data and we were not able to draw conclusions from these studies. We found no other randomised studies that investigated interventions for disorders of eye movement in patients with stroke.

\section{Overall completeness and applicability of evidence}

Both identified studies investigated pharmacological interventions for the eye movement disorder of nystagmus. Strupp 2003 compared an active pharmacological intervention with an inactive placebo intervention, while Leigh 1991 was designed as a placebo control trial but was later determined to compare two different active pharmacological interventions. It was, therefore, not appropriate to combine the results within a meta-analysis.

Both studies had a very small number of participants (total 38) and there were only a total of five participants with stroke. In the paper that compared the intervention to placebo (Strupp 2003), the results within the stroke subgroup were different to the patients with other aetiologies. This suggests that these patients may not respond to the treatment in the same way. This limits the evidence for the effectiveness of this intervention and its proposed mode of action in those patients with nystagmus following stroke. There is, therefore, clearly insufficient evidence from which to draw any conclusions relating to participants with stroke.

\section{Quality of the evidence}

We judged both included studies to have appropriate allocation concealment and blinding, and assessed neither to have 'other' potential sources of bias. However, Leigh 1991 reported a high dropout rate and we judged that incomplete outcome data were not addressed adequately. There was insufficient information to judge whether incomplete outcome data were appropriately addressed by Strupp 2003.

\section{Potential biases in the review process}

\section{Publication bias}

Through a thorough searching process we are confident we should have identified all relevant published studies. However, it must be acknowledged that there is a possibility that there are additional studies (published and unpublished) that we did not identify. Many of the orthoptic journals were not included in the main databases of research journals covered by our search strategy; however these were handsearched by one review author (FR).

\section{Categorisation of interventions}

We had planned to categorise all interventions as either restitutive, substitutive, compensative or assessment and screening interventions. However, we had not anticipated the identification of pharmacological interventions when we developed these categories. We were unable to agree in which of the defined categories the pharmacological interventions should be included and, after discussion, we reached consensus that a new category was needed. As this decision did not alter any subsequent comparison or analysis we do not feel that this introduced bias into the review process.

\section{Studies awaiting classification}

We have identified one study (Hofferberth 1995), described as a controlled trial, which investigates saccadic eye movement training in 100 patients with stroke. We have been unable to contact the study authors to confirm if participants were randomised or not, although information in the published report suggests that the control group comprised 'healthy' participants. If this study is a RCT then this will contribute a substantial quantity of evidence to this review.

Muchnick 1998 is a comparison study of surgical interventions for unilateral superior oblique muscle paresis. There are no data on the method of allocation nor on the cause of the paresis and thus 
it is not particularly likely to be relevant to this review. We have been unable to contact the study authors to clarify these issues.

\section{Agreements and disagreements with other studies or reviews}

Th Scottish Intercollegiate Guideline Network (SIGN) guidelines for stroke rehabilitation state that there is "almost no evidence relating to interventions for eye movement disorders" and was based on three reviews (Barrett 2009; Jones 2006; Riggs 2007), each of which had 'methodological limitations'. Neither the Barrett 2009 nor the Riggs 2007 review identified primary evidence relating to eye movement disorders in patients with stroke. Our review agrees with this finding as to the lack of evidence.

\section{AUTHORS, CONCLUSIONS}

\section{Implications for practice}

There is insufficient evidence to reach conclusions about the effectiveness of interventions for patients with eye movement disorders after stroke.

\section{Implications for research}

There is currently an absence of relevant evidence. High-quality research is, therefore, urgently required.

\section{Are randomised controlled trials required?}

Randomised controlled trials (RCTs) are urgently required to determine the effects of clinically relevant rehabilitation interventions and pharmacological interventions in stroke patients compared to no treatment, placebo or usual care.

We recommend that such RCTs must:

1. have adequate power (i.e. with an appropriate power calculation undertaken based on evidence from phase I and II studies);

2. have adequate allocation concealment, blinding of outcome assessor and intention-to-treat analysis;

3. clearly define trial participants; we recommend trials that include populations with the most common eye movement disorders of cranial nerve palsies, manifest strabismus, saccadic palsy and dysmetria, nystagmus and reduced convergence;

4. specifically recruit patients whose eye movement disorders are due to stroke;

5. include measures of functional ability in activities of daily living, visual function (including reading measures) and visionrelated quality of life;

6. report clear and usable data.
We recommend that future RCTs concentrate on answering the specific question relating to the effectiveness of interventions compared with control, placebo, no treatment or usual care rather than comparisons with variations of the same 'type' or category of intervention, or comparisons of different doses, adjuncts to treatment or modes of delivery. We believe that until such time as the benefits of interventions for eye movement disorders compared with control, placebo, no treatment or usual care have been established (or refuted) it is not beneficial to compare the relative effects of different interventions.

\section{Are other primary research studies required?}

Other primary research studies may be required in preparation for well-designed RCTs. In order to predict recruitment rates and plan future RCTs it would be useful to have clear information regarding the prevalence of eye-movement disorders within the stroke population at defined post-stroke time points.

\section{Are further systematic reviews required?}

We recommend that systematic reviews of RCTs of interventions for eye movement disorders with a neurological cause, but without a specific stroke aetiology, are carried out. There are a number of relevant RCTs and such systematic reviews may be used to support current management for individual patients in the absence of stroke-specific RCTs. There are already a number of Cochrane reviews synthesising the evidence from non-stroke populations, including reviews of botulinum toxin for the treatment of strabismus (Rowe 2009c) and adjustable versus non-adjustable sutures for strabismus (Haridas 2005).

We recommend systematic reviews of non-randomised studies of interventions for eye movement disorders in patients with stroke in order to synthesise the current evidence base, to guide current practice, and to aid in the development of well-designed RCTs. Systematic reviews of evidence of the effectiveness of interventions for specific eye movement disorders in participants with mixed aetiologies may provide evidence which is relevant and transferable to the population of patients with eye movement disorders as a result of stroke.

We recommend that this review is updated to identify and include any further RCTs. We did identify one ongoing study investigating prismatic spectacle lenses on symptoms of dizziness, headache and anxiety caused by vertical heterophoria. The researchers have confirmed that this study does include patients with stroke and it may therefore be relevant for future updates of this review.

\section{ACKNOWLEDGEMENTS}

We would like to thank Brenda Thomas and Marion Kelt for their help in developing the search strategy. 


\section{R E F E R E N C E S}

\section{References to studies included in this review}

Leigh 1991 \{published data only\}

Leigh RJ, Burnstine TH, Ruff RL, Kasmer RJ. Effect of anticholinergic agents upon acquired nystagmus: a doubleblind study of trihexyphenidyl and trihexethyl chloride. Neurology 1991;41:1737-41.

Strupp 2003 \{published data only\}

Strupp M, Schuler O, Krafczyk S, Jahn K, Schautzer F, Buttner U, et al. Treatment of downbeat nystagmus with 3, 4-diaminopyridine. Neurology 2003;61:165-70.

\section{References to studies excluded from this review}

Repka 1989 \{published data only\}

Prism Adaptation Study Research Group. Efficacy of prism adaptation in the surgical management of acquired esotropia. Archives of Ophthalmology 1990;108:1248-56.

\section{References to studies awaiting assessment}

Hofferberth 1995 \{published data only\}

Hofferberth B. Results from training saccadic eye movements in stroke patients [Ergebnisse des Sakkadentrainings bei Schlaganfall-Patienten]. Nervenheilkunde 1995;14:319-20.

Muchnick 1998 \{published data only\}

Muchnick RS, McCullough DH, Strominger MB. Comparison of anterior transposition and recession of the inferior oblique muscle in unilateral superior oblique paresis. Journal of American Association for Pediatric Ophthalmology and Strabismus 1998;2(6):340-3.

\section{References to ongoing studies}

Rosner 2010 \{published data only\}

Rosner M. Effects of prismatic spectacle lenses on symptoms of dizziness, headache, anxiety as caused by vertical heterophoria. clinicaltrials.gov 2010.

\section{Additional references}

\section{Barrett 2009}

Barrett BT. A critical evaluation of the evidence supporting the practice of behavioural vision therapy. Ophthalmic and Physiological Optics 2009;29:4-25.

Berg 1989

Berg KO, Wood-Dauphinee S, Williams JI, Gayton D. Measuring balance in the elderly: preliminary development of an instrument. Physiotherapy Canada 1989;41:304-11.

Ciuffreda 2007

Ciuffreda KJ, Kapoor N, Rutner D, Suchoff IB, Han ME, Craig S. Occurrence of oculomotor dysfunctions in acquired brain injury: a retrospective analysis. Optometry 2007;78(4):155-61.

\section{Ciuffreda 2008}

Ciuffreda KJ, Rutner D, Kapoor N, Suchoff IB, Craig S, Ha ME. Vision therapy for oculomotor dysfunctions in acquired brain injury: a retrospective analysis. Optometry 2008;79:18-22.

\section{Clisby 1995}

Clisby C. Visual assessment of patients with cerebrovascular accident on the elderly care wards. British Orthoptic Journal 1995;52:38-41.

\section{Deeks 2001}

Deeks JJ, Altman DG, Bradburn MJ. Statistical methods for examining heterogeneity and combining results from several studies in meta-analysis. In: Egger M, Davey Smith G, Altman DG editor(s). Systematic Reviews in Health Care. 2nd Edition. London, UK: BMJ Books, 2001:300.

Duncan 1990

Duncan PW, Weiner DK, Chandler J, Studenski S. Functional reach: a new clinical measure of balance. Journal of Gerontology 1990;45(6):M192-7.

\section{Freeman 1987}

Freman CF, Rudge DB. The orthoptist's role in the management of stroke patients. Transactions of the Sixth International Orthoptic Congress. 1987:333-7.

Haridas 2005

Haridas A, Sundaram V. Adjustable versus nonadjustable sutures for strabismus. Cochrane Database of Systematic Reviews 2005, Issue 1. [DOI: 10.1002/ 14651858.CD004240.pub2]

Holbrook 1983

Holbrook M, Skilbeck CE. An activities index for use with stroke patients. Age and Ageing 1983;12:166-70.

Jones 2006

Jones SA, Shinton RA. Improving outcome in stroke patients with visual problems. Age and Ageing 2006;35: $560-5$.

Katz 1963

Katz S, Ford AB. Studies of illness in the aged. The Index of ADL: a standardised measure of biological and psychosocial function. Journal of the American Medical Association 1963; 185:914-9.

\section{Kerkhoff 1999}

Kerkhoff G. Restorative and compensatory therapy approaches in cerebral blindness - a review. Restorative Neurology and Neuroscience 1999;15:255-71.

\section{Kerkhoff 2000}

Kerkhoff G. Neurovisual rehabilitation: recent developments and future directions. Journal of Neurology, Neurosurgery and Psychiatry 2000;68:691-706.

\section{MacIntosh 2003}

MacIntosh C. Stroke re-visited: visual problems following stroke and their effect on rehabilitation. British Orthoptic Journal 2003;60:10-4.

\section{Mahoney 1965}

Mahoney FI, Barthel DW. Functional evaluation: the Barthel Index. Maryland State Medical Journal 1965; February:61-5. 
Mathias 1986

Mathias S, Nayak U, Isaacs B. Balance in elderly patients: the "Get-up and Go" test. Archives of Physical Medicine and Rehabilitation 1986;67:387-9.

Pederson 1981

Pederson RA, Troost BT. Abnormalities of gaze in cerebrovascular disease. Stroke 1981;12(2):251-4.

\section{RevMan 2011 [Computer program]}

The Nordic Cochrane Centre, The Cochrane Collaboration. Review Manager (RevMan). Version 5.1. Copenhagen: The Nordic Cochrane Centre, The Cochrane Collaboration, 2011.

\section{Riggs 2007}

Riggs RV, Andrews K, Roberts P, Gilewski M. Visual deficit interventions in adult stroke and brain injury. American Journal of Physical Medicine and Rehabilitation 2007;86: $853-60$.

Rowe 2009a

Rowe F, Brand D, Jackson CA, Price A, Walker L, Harrison $S$, et al. Visual impairment following stroke: do stroke patients require vision assessment?. Age and Ageing 2009; 38:188-93.

\section{Rowe 2009b}

Rowe F, VIS Group. The profile of strabismus in stroke survivors. Eye 2010; Vol. 24, issue 4:682-5. [DOI: 10.1038/eye.2009.138]

Rowe 2009c

Rowe FJ, Noonan CP. Botulinum toxin for the treatment of strabismus. Cochrane Database of Systematic Reviews 2009, Issue 2. [DOI: 10.1002/14651858.CD006499.pub2]

\section{Smith 1990}

Smith P, Hamilton BB, Granger CV. The fone FIM. Buffalo, New York: Research Foundation of the State University of New York, 1990.

\section{Tinetti 1990}

Tinetti ME, Richman D, Powell L. Falls efficacy as a measure of falling. Journal of Gerontology 1990;45(6): $239-43$.

\section{Wolter 2006}

Wolter M, Preda S. Visual deficits following stroke: maximising participation in rehabilitation. Topics in Stroke Rehabilitation 2006;13(3):12-21.

* Indicates the major publication for the study 


\section{CHARACTERISTICS OF STUDIES}

\section{Characteristics of included studies [ordered by study ID]}

\section{Leigh 1991}

\begin{tabular}{|c|c|c|}
\hline Methods & \multicolumn{2}{|c|}{$\begin{array}{l}\text { Randomised double-blind cross-over trial } \\
\text { Patients "randomly assigned", no further information available }\end{array}$} \\
\hline Participants & \multicolumn{2}{|c|}{$\begin{array}{l}10 \text { participants with impaired vision and oscillopsia due to acquired nystagmus } \\
\text { Exclusion criteria: glaucoma, cardiac disease, COPD, bowel disease } \\
\text { The number assigned to each group is not clearly stated. } \\
\text { Method of diagnosing eye movement disorder: presence of oscillopsia, movements of } \\
\text { eye measured using magnetic search coil technique }\end{array}$} \\
\hline Interventions & \multicolumn{2}{|c|}{$\begin{array}{l}\text { Group 1: Drug A: trihexyphenidyl } 5 \mathrm{mg} \text { capsules } 1 \text { capsule per day. Drug dosage increased } \\
1 \text { tablet per week until taking } 4 \text { tablets per day } \\
\text { Group 2: Drug B: tridihexethyl chloride } 25 \mathrm{mg} 1 \text { capsule per day. Drug dosage increased } \\
1 \text { tablet per week until taking } 4 \text { tablets per day } \\
1 \text { to 2-week washout period followed by swap to other tablet }\end{array}$} \\
\hline Outcomes & \multicolumn{2}{|c|}{$\begin{array}{l}\text { Visual Acuity (Snellen) } \\
\text { Nystagmus: horizontal, vertical and torsional movements by magnetic search coil tech- } \\
\text { nique }\end{array}$} \\
\hline Notes & \multicolumn{2}{|c|}{$\begin{array}{l}\text { Only } 2 \text { included participants had a stroke - of these only } 1 \text { actually took part in the trial, } \\
\text { taking only tridihexethyl chloride } \\
\text { Drug B (tridihexethyl chloride) was meant to be an active control, it is "an anti-cholin- } \\
\text { ergic agent used for the treatment of peptic ulcer ... and ... would not be expected to } \\
\text { cross the blood-brain barrier". However it was found to produce effects on the outcomes } \\
\text { measured } \\
\text { This was a cross-over trial, with participant changing to the other treatment after } 1 \text { to } 2 \\
\text { weeks with no treatment }\end{array}$} \\
\hline \multicolumn{3}{|l|}{ Risk of bias } \\
\hline Bias & Authors' judgement & Support for judgement \\
\hline Allocation concealment (selection bias) & Low risk & $\begin{array}{l}\text { "Randomly assigned", no further details } \\
\text { Quote "both medications were identical } \\
\text { in appearance", no further information on } \\
\text { concealment of allocation }\end{array}$ \\
\hline $\begin{array}{l}\text { Blinding (performance bias and detection } \\
\text { bias) } \\
\text { All outcomes }\end{array}$ & Low risk & $\begin{array}{l}\text { Masking of assessor is not described. How- } \\
\text { ever, participants and assessor should both } \\
\text { be masked as "both medications were iden- } \\
\text { tical in appearance" }\end{array}$ \\
\hline
\end{tabular}

Interventions for disorders of eye movement in patients with stroke (Review)

Copyright () 201 I The Cochrane Collaboration. Published by John Wiley \& Sons, Ltd. 


\section{Leigh 1991 (Continued)}

\begin{tabular}{|l|l|l|}
\hline $\begin{array}{l}\text { Incomplete outcome data (attrition bias) } \\
\text { All outcomes }\end{array}$ & High risk & $\begin{array}{l}\text { Only 5 participants completed both Drug } \\
\text { A and Drug B (cross-over phases). 1 partic- } \\
\text { ipant completed Drug A only, 1 completed } \\
\text { Drug B only and 3 completed neither of } \\
\text { the drug interventions } \\
2 \text { participants were unable to tolerate Drug } \\
\text { A, 1 unable to tolerate B, 1 dropped out } \\
\text { after Drug A as MS relapsed, 1 dropped out } \\
\text { due to unrelated peripheral vascular disease }\end{array}$ \\
\hline Other bias & Low risk & \begin{tabular}{l} 
No other potential source of bias noted \\
\hline
\end{tabular}
\end{tabular}

\section{Strupp 2003}

Methods

Prospective randomised controlled double-blind cross-over trial

Method of randomisation: computer-generated randomisation list

\begin{tabular}{l} 
Participants \\
$\begin{array}{l}\text { Particpants had down-beat nystagmus, either pure or with co-existent eye movement } \\
\text { problems, but were excluded if they had epilepsy, cardiac arrhythmias, or took drugs that } \\
\text { may affect nervous or vestibular system } \\
\text { Group 1: } 8 \text { participants, Group 2: } 9 \text { participants; } 3 / 17 \text { had stroke diagnosis (cerebellar } \\
\text { infarction) } \\
\text { Method of diagnosing eye movement disorder: neuro-ophthalmologic and neuro-oto- } \\
\text { logic examination. Electronystagmography and neuro-orthoptic examination (includ- } \\
\text { ing fundus photography and determination of subjective vision) }\end{array}$ \\
\hline
\end{tabular}

Interventions

Group 1 (pharmacological intervention) $20 \mathrm{mg}$ capsule of 3,4 diaminopyridine (DAP) and lactose

Group 2 (placebo) lactose capsule

Outcomes

Horizontal and vertical eye movements: 2D video-oculography; this was measured 30 minutes after taking the capsule

Questioned as to intensity of oscillopsia (but not recorded)

Side-effect questionnaire 30 and 60 minutes after tablets taken

Notes Cross over study - data analysed as single group

The results of the 3 stroke patients was different to the patients with cerebellar degeneration, suggesting that these patients may not respond to the treatment in the same way

\section{Risk of bias}

\section{Bias}

Allocation concealment (selection bias)
Authors' judgement

Low risk

\section{Support for judgement}

"With use of a computer-generated randomization list, each subject was assigned by the investigator to initially receive 3,4- 


\begin{tabular}{|c|c|c|}
\hline & & $\begin{array}{l}\text { DAP or placebo at least } 1 \text { week (washout } \\
\text { period) later. Code envelopes were kept by } \\
\text { the investigator during the trial and re- } \\
\text { turned unopened to the monitor after ter- } \\
\text { mination of the study. The blind was main- } \\
\text { tained until data analysis had been com- } \\
\text { pleted." }\end{array}$ \\
\hline $\begin{array}{l}\text { Blinding (performance bias and detection } \\
\text { bias) } \\
\text { All outcomes }\end{array}$ & Low risk & $\begin{array}{l}\text { "With use of a computer-generated ran- } \\
\text { domization list, each subject was assigned } \\
\text { by the investigator to initially receive 3,4- } \\
\text { DAP or placebo at least } 1 \text { week (washout } \\
\text { period) later. Code envelopes were kept by } \\
\text { the investigator during the trial and re- } \\
\text { turned unopened to the monitor after ter- } \\
\text { mination of the study. The blind was main- } \\
\text { tained until data analysis had been com- } \\
\text { pleted." } \\
\text { "3,4-DAP and placebo. Capsules with } 20 \\
\text { mg of 3,4-DAP and lactose or placebo } \\
\text { (a capsule with lactose alone) were man- } \\
\text { ufactured and delivered by the pharmacy } \\
\text { of the University of Munich (Klinikum } \\
\text { Grosshadern). The shape and colour of the } \\
\text { capsules with 3,4-DAP or placebo were } \\
\text { identical. The generic drug for 3,4-DAP } \\
\text { was delivered by Synopharm GmbH Phar- } \\
\text { maceutical Co (Barsbuttel, Germany) to } \\
\text { our pharmacy." }\end{array}$ \\
\hline $\begin{array}{l}\text { Incomplete outcome data (attrition bias) } \\
\text { All outcomes }\end{array}$ & Unclear risk & $\begin{array}{l}1 \text { participant was excluded before start of } \\
\text { intervention due to chronic alcohol abuse } \\
\text { The subjective comments regarding the } \\
\text { severity of oscillopsia not presented }\end{array}$ \\
\hline Other bias & Low risk & No other potential source of bias noted \\
\hline
\end{tabular}

COPD: chronic obstructive pulmonary disease

MS: multiple sclerosis 
Characteristics of excluded studies [ordered by study ID]

\begin{tabular}{ll}
\hline Study & Reason for exclusion \\
\hline Repka 1989 & $\begin{array}{l}\text { This study included those with acquired and not congenital esotropia, so could have included those caused by a stroke. } \\
\text { Correspondence with the authors informed us that stroke survivors would not have been eligible to enter their trial, } \\
\text { so this study is not relevant to the review }\end{array}$ \\
\hline
\end{tabular}

\section{Characteristics of studies awaiting assessment [ordered by study ID]}

\section{Hofferberth 1995}

\begin{tabular}{ll}
\hline Methods & Controlled clinical trial \\
\hline Participants & Ischaemic stroke - 100 trained, 100 not trained (plus 100 normal controls) \\
\hline Interventions & 100 saccadic eye movement training, 100 no treatment \\
\hline Outcomes & Saccadic velocity, number-connection test, spatial orientation \\
\hline Notes & $\begin{array}{l}\text { There is no mention of how patients were allocated to treatment groups; attempts to contact the author have so far } \\
\text { yielded no results }\end{array}$ \\
\hline
\end{tabular}

\section{Muchnick 1998}

\begin{tabular}{ll}
\hline Methods & Comparison study \\
\hline Participants & 9 patients with Knapp's class III unilateral superior oblique muscle paresis; aetiology not recorded \\
\hline Interventions & Surgical intervention: 4 had $14 \mathrm{~mm}$ recession surgery, 5 had anterior transposition of the superior oblique muscle \\
\hline Outcomes & Magnitude of deviation in the primary position and 8 cardinal positions of gaze \\
\hline Notes & $\begin{array}{l}\text { There is no mention of how patients were allocated to treatment groups; attempts to contact the author have so far } \\
\text { yielded no results }\end{array}$ \\
\hline
\end{tabular}

\section{Characteristics of ongoing studies [ordered by study ID]}

\section{Rosner 2010}

Trial name or title Effects of prismatic spectacle lenses on symptoms of dizziness, headache and anxiety as caused by vertical heterophoria

Methods

Randomised, double-blind cross-over study 
Rosner 2010 (Continued)

\begin{tabular}{ll} 
Participants & $\begin{array}{l}\text { Symptoms of dizziness and/or headache lasting longer than } 4 \text { months and diagnosed with a vertical het- } \\
\text { erophoria }\end{array}$ \\
\hline $\begin{array}{l}\text { Interventions } \\
\text { Intervention: lenses containing prismatic correction } \\
\text { Placebo: lenses not containing prismatic correction }\end{array}$ \\
\hline Outcomes & Symptomatology self-survey tools \\
\hline Starting date & November 2008 \\
\hline Contact information & Mark S Rosner, MD msr50@comcast.net \\
\hline Notes & $\begin{array}{l}\text { Due to finish December } 2010 \\
\text { Correspondence with the author confirms that a number of the participants' phorias are as a consequence of } \\
\text { stroke }\end{array}$ \\
\hline
\end{tabular}




\section{DATA ANDANALYSES}

This review has no analyses.

\section{ADDITIONAL TABLES}

Table 1. Demographics of included studies: settings of included studies

\begin{tabular}{lll}
\hline Study & Leigh 1991 & Strupp 2003 \\
\hline Country & USA & Germany \\
\hline Setting for Intervention & Not stated & Outpatient clinic \\
\hline
\end{tabular}

Table 2. Demographics of included studies: demographics of included participants

\begin{tabular}{|c|c|c|}
\hline Study & Leigh 1991 & Strupp 2003 \\
\hline No. of participants & 10 & 17 \\
\hline Age & $\begin{array}{l}\text { Range } 23 \text { to } 82 \text { years } \\
\text { Mean } 46.1 \\
\text { SD } 18.14\end{array}$ & $\begin{array}{l}50 \text { to } 85 \text { years } \\
\text { Mean } 67.64 \\
\text { SD } 9.92\end{array}$ \\
\hline Gender & $\begin{array}{l}5 \text { female } \\
5 \text { male }\end{array}$ & $\begin{array}{l}8 \text { female } \\
9 \text { male }\end{array}$ \\
\hline Time since stroke/lesion & Not stated & $\begin{array}{l}\text { Of infarct ( } 3 \text { patients) } \\
\text { Range } 6 \text { to } 36 \text { months }\end{array}$ \\
\hline Initial functional ability & Not stated & Not stated \\
\hline Type of stroke/lesion & $\begin{array}{l}1 \text { post-surgical hypoxia } \\
2 \text { infarction } \\
6 \mathrm{MS} \\
1 \text { cerebellar degeneration }\end{array}$ & $\begin{array}{l}\text { Cerebellar atrophy } 5 \\
\text { Infarction } 3 \\
\text { Arnold-Chiari Malformation } 1 \\
\text { Unknown } 8\end{array}$ \\
\hline Side of stroke/lesion & Not stated & $\begin{array}{l}\text { Of infarct } \\
\text { R } 2 \\
\text { Midline } 1\end{array}$ \\
\hline
\end{tabular}

MS: multiple

SD: standard deviation 
Table 3. Demographics of included studies: disorders of eye movements

\begin{tabular}{|c|c|c|}
\hline Study & Leigh 1991 & Strupp 2003 \\
\hline Type of eye movement disorder & Nystagmus & Downbeat nystagmus \\
\hline $\begin{array}{l}\text { Deviation of eye movement } \\
\text { (horizontal, vertical, torsional) }\end{array}$ & $\begin{array}{l}1 \text { seesaw } \\
2 \text { torsional } \\
2 \text { downbeat } \\
5 \text { pendular/elliptical }\end{array}$ & Downbeat \\
\hline $\begin{array}{l}\text { Severity of eye movement disorder } \\
\text { (slight/small/moderate/severe)(paralysis/ } \\
\text { paresis) (monocular/binocular) }\end{array}$ & Not stated & $\begin{array}{l}\text { Not stated } \\
\text { NB: variety of additional eye movement } \\
\text { disorders including rebound nystagmus ( } \\
=6) \text {, hypermetric saccades }(\mathrm{N}=2) \text { and } \\
\text { fourth nerve palsy }(\mathrm{N}=1)\end{array}$ \\
\hline Age-related eye problems? Yes/No & $\begin{array}{l}\text { Not stated } \\
\text { (glaucoma is an exclusion criterion) }\end{array}$ & Not stated \\
\hline Visual field impairment? Yes/No & No & Not stated \\
\hline Visual inattention? Yes/No & No & No \\
\hline $\begin{array}{l}\text { Level of motor impairment ( } \mathrm{mild} / \mathrm{mod} \text { - } \\
\text { erate/severe) }\end{array}$ & Not stated & Not stated \\
\hline $\begin{array}{l}\text { Level of cognitive impairment (mild/ } \\
\text { moderate/severe) }\end{array}$ & Not stated & Not stated \\
\hline
\end{tabular}

\section{A P PEN DICES}

\section{Appendix I. CENTRAL (The Cochrane Library) search strategy}

To avoid duplication of effort we designed broad search strategies for the major databases sensitive enough to cover the scope of a series of three Cochrane reviews of interventions for different visual disorders following stroke. We devised the following search strategy, using a combination of controlled vocabulary (MeSH) and free text terms, for MEDLINE and modified it to suit other databases: MEDLINE (Appendix 2); EMBASE (Ovid) (Appendix 3); CINAHL (EBSCO) (Appendix 4); AMED (Ovid) (Appendix 5); PsycINFO (Ovid) (Appendix 6).

1. MeSH descriptor Cerebrovascular Disorders, this term only

2. MeSH descriptor Basal Ganglia Cerebrovascular Disease explode all trees

3. $\mathrm{MeSH}$ descriptor Brain Ischemia explode all trees

4. MeSH descriptor Carotid Artery Diseases explode all trees

5. MeSH descriptor Intracranial Arterial Diseases explode all trees

6. MeSH descriptor Intracranial Arteriovenous Malformations explode all trees

7. MeSH descriptor Intracranial Embolism and Thrombosis explode all trees 
8. MeSH descriptor Intracranial Hemorrhages explode all trees

9. $\mathrm{MeSH}$ descriptor Stroke explode all trees

10. MeSH descriptor Brain Infarction explode all trees

11. MeSH descriptor Vasospasm, Intracranial, this term only

12. $\mathrm{MeSH}$ descriptor Vertebral Artery Dissection, this term only

13. stroke or poststroke or post-stroke or cerebrovasc* or brain vasc* or cerebral vasc* or cva* or apoplex* or SAH

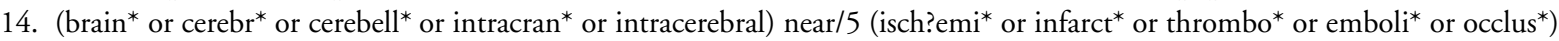

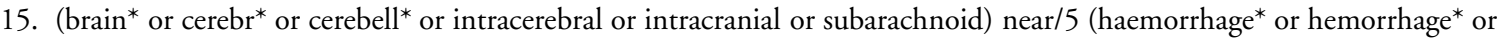

haematoma* or hematoma* or bleed*)

16. MeSH descriptor Hemiplegia, this term only

17. MeSH descriptor Paresis explode all trees

18. hemipleg* or hemipar* or paresis or paretic 1735

19. (\#1 OR \#2 OR \#3 OR \#4 OR \#5 OR \#6 OR \#7 OR \#8 OR \#9 OR \#10 OR \#11 OR \#12 OR \#13 OR \#14 OR \#15 OR \#16

OR \#17 OR \#18)

20. MeSH descriptor Eye explode all trees

21. MeSH descriptor Visually Impaired Persons explode all trees

22. MeSH descriptor Ocular Physiological Processes explode all trees

23. MeSH descriptor Diagnostic Techniques, Ophthalmological explode all trees

24. $\mathrm{MeSH}$ descriptor Optometry explode all trees

25. MeSH descriptor Orthoptics explode all trees

26. MeSH descriptor Eye Diseases, this term only

27. MeSH descriptor Vision Disorders, this term only

28. MeSH descriptor Eye Manifestations, this term only

29. $\mathrm{MeSH}$ descriptor Blindness, this term only

30. MeSH descriptor Diplopia explode all trees

31. MeSH descriptor Vision, Binocular, this term only

32. MeSH descriptor Vision, Monocular, this term only

33. MeSH descriptor Visual Acuity explode all trees

34. MeSH descriptor Visual Fields, this term only

35. MeSH descriptor Vision, Low, this term only

36. $\mathrm{MeSH}$ descriptor Perimetry, this term only

37. MeSH descriptor Ophthalmology, this term only

38. MeSH descriptor Vision Screening, this term only

39. $\mathrm{MeSH}$ descriptor Eye Diseases, Hereditary explode all trees

40. MeSH descriptor Eye Hemorrhage explode all trees

41. MeSH descriptor Lacrimal Apparatus Diseases explode all trees

42. $\mathrm{MeSH}$ descriptor Lens Diseases explode all trees

43. $\mathrm{MeSH}$ descriptor Ocular Hypertension explode all trees

44. MeSH descriptor Ocular Hypotension explode all trees

45. MeSH descriptor Ocular Motility Disorders explode all trees

46. MeSH descriptor Optic Nerve Diseases explode all trees

47. $\mathrm{MeSH}$ descriptor Orbital Diseases explode all trees

48. MeSH descriptor Pupil Disorders explode all trees

49. MeSH descriptor Refractive Errors explode all trees

50. MeSH descriptor Retinal Diseases explode all trees

51. MeSH descriptor Blindness, Cortical explode all trees

52. MeSH descriptor Hemianopsia explode all trees

53. MeSH descriptor Vitreoretinopathy, Proliferative explode all trees

54. MeSH descriptor Vitreous Detachment explode all trees

55. MeSH descriptor Scotoma, this term only

56. MeSH descriptor Abducens Nerve, this term only

57. MeSH descriptor Oculomotor Nerve, this term only

58. MeSH descriptor Trochlear Nerve, this term only

Interventions for disorders of eye movement in patients with stroke (Review)

Copyright @ 201 I The Cochrane Collaboration. Published by John Wiley \& Sons, Ltd. 
59. nystagmus or smooth pursuit or saccades or depth perception or stereopsis or gaze disorder* or retinal or retinopathy or macular degeneration or glaucoma or cataract* or ophthalmol* or optic nerve

60. intranuclear ophthalmoplegia or parinaud's syndrome or weber's syndrome or skew deviation or conjugate deviation

61. one near/3 half syndrome

62. (visual ${ }^{*}$ or vision or eye or eyes or eyesight or sight) near/5 (problem* or disorder* or impair* or disabilit* or loss or disease* ${ }^{*}$ defect* or manifestation* or screening or test* or examination*)

63. hemianop* or blindness or low vision or refractive errors or vitreoretinopathy or vitreous detachment or scotoma or diplopia or optometr* or ocular or orthoptic*

64. oscillopsia or visual tracking or fresnel prism*

65. III or IV or VI or third or fourth or sixth near/3 nerve palsy

66. (\#20 OR \#21 OR \#22 OR \#23 OR \#24 OR \#25 OR \#26 OR \#27 OR\#28 OR \#29 OR \#30 OR\#31 OR \#32 OR\#33 OR\# 34 OR \#35 OR \#36 OR\#37 OR\#38 OR \#39 OR \#40 OR \#41 OR\#42 OR\#43 OR \#44 OR \#45 OR \#46 OR \#47 OR \#48 OR\# 49 OR \#50 OR \#51 OR \#52 OR \#53 OR \#54 OR \#55 OR \#56 OR \#57 OR \#58 OR \#59 OR \#60 OR \#61 OR \#62 OR \#63 OR \# 64 OR \#65)

67. (\#19 AND \#66)

68. MeSH descriptor Infant explode all trees

69. MeSH descriptor Child explode all trees

70. neonat* or child or children or childhood or juvenile or infan* or toddler

71. MeSH descriptor Neoplasms explode all trees

72. cancer* or carcinoma* or tumor* or tumour* or neoplasm*

73. (\#68 OR \#69 OR\#70 OR\#71 OR\#72)

74. (\#67 AND NOT \#73)

\section{Appendix 2. MEDLINE (Ovid) search strategy}

1. cerebrovascular disorders/ or exp basal ganglia cerebrovascular disease/ or exp brain ischemia/ or exp carotid artery diseases/ or exp intracranial arterial diseases/ or exp intracranial arteriovenous malformations/ or exp "intracranial embolism and thrombosis"/ or exp intracranial hemorrhages/ or stroke/ or exp brain infarction/ or vasospasm, intracranial/ or vertebral artery dissection/

2. (stroke or poststroke or post-stroke or cerebrovasc $\$$ or brain vasc $\$$ or cerebral vasc $\$$ or cva $\$$ or apoplex $\$$ or SAH).tw.

3. ((brain $\$$ or cerebr $\$$ or cerebell $\$$ or intracran $\$$ or intracerebral) adj5 (isch?emi $\$$ or infarct $\$$ or thrombo $\$$ or emboli $\$$ or occlus $\$)$ ).tw.

4. ((brain $\$$ or cerebr $\$$ or cerebell\$ or intracerebral or intracranial or subarachnoid) adj5 (haemorrhage $\$$ or hemorrhage $\$$ or haematoma $\$$ or hematoma $\$$ or bleed $\$)$ ).tw.

5. hemiplegia/ or exp paresis/

6. (hemipleg\$ or hemipar $\$$ or paresis or paretic).tw.

7. 1 or 2 or 3 or 4 or 5 or 6

8. exp eye/

9. exp visually impaired persons/

10. exp ocular physiological processes/ or exp diagnostic techniques, ophthalmological/

11. Optometry/ or Orthoptics/

12. eye diseases/ or vision disorders/ or eye manifestations/ or blindness/ or diplopia/

13. vision, binocular/ or vision, monocular/ or exp visual acuity/ or visual fields/ or vision, low/ or perimetry/or ophthalmology/or vision screening/

14. exp eye diseases, hereditary/ or exp eye hemorrhage/ or exp lacrimal apparatus diseases/ or exp lens diseases/ or exp ocular hypertension/ or exp ocular hypotension/ or exp ocular motility disorders/ or exp optic nerve diseases/ or exp orbital diseases/ or exp pupil disorders/ or exp refractive errors/ or exp retinal diseases/ or exp blindness, cortical/ or exp hemianopsia/ or exp vitreoretinopathy, proliferative/ or exp vitreous detachment/ or scotoma/

15. abducens nerve/ or oculomotor nerve/ or trochlear nerve/

16. (nystagmus or smooth pursuit or saccades or depth perception or stereopsis or gaze disorder\$ or retinal or retinopathy or macular degeneration or glaucoma or cataract $\$$ or ophthalmol $\$$ or optic nerve).tw.

17. (intranuclear ophthalmoplegia or parinaud's syndrome or weber's syndrome or skew deviation or conjugate deviation or (one adj3 half syndrome)).tw

Interventions for disorders of eye movement in patients with stroke (Review)

Copyright @ 201 I The Cochrane Collaboration. Published by John Wiley \& Sons, Ltd. 
18. ((visual $\$$ or vision or eye or eyes or eyesight or sight) adj5 (problem\$ or disorder $\$$ or impair $\$$ or disabilit $\$$ or loss or disease $\$$ or defect $\$$ or manifestation $\$$ or screening or test $\$$ or examination $\$)$ ).tw.

19. (hemianop\$ or blindness or low vision or refractive errors or vitreoretinopathy or vitreous detachment or scotoma or diplopia or optometr\$ or ocular or orthoptic\$).tw.

20. (oscillopsia or visual tracking or fresnel prism\$).tw

21. ((III or IV or VI or third or fourth or sixth) adj3 nerve palsy).tw

22. 8 or 9 or 10 or 11 or 12 or 13 or 14 or 15 or 16 or 17 or 18 or 19 or 20 or 21

23.7 and 22

24. Randomized Controlled Trials as Topic/

25. random allocation/

26. Controlled Clinical Trials as Topic/

27. control groups/

28. clinical trials as topic/ or clinical trials, phase i as topic/ or clinical trials, phase ii as topic/ or clinical trials, phase iii as topic/ or clinical trials, phase iv as topic/

29. double-blind method/

30. single-blind method/

31. Placebos/

32. placebo effect/

33. cross-over studies/

34. Multicenter Studies as Topic/

35. Therapies, Investigational/

36. Drug Evaluation/

37. Research Design/

38. Program Evaluation/

39. evaluation studies as topic/

40. randomized controlled trial.pt.

41. controlled clinical trial.pt.

42. (clinical trial or clinical trial phase i or clinical trial phase ii or clinical trial phase iii or clinical trial phase iv).pt.

43. multicenter study.pt.

44. (evaluation studies or comparative study).pt.

45. random\$.tw.

46. (controlled adj5 (trial\$ or stud\$)).tw.

47. (clinical\$ adj5 trial\$).tw.

48. ((control or treatment or experiment\$ or intervention) adj5 (group\$ or subject\$ or patient\$)).tw.

49. (quasi-random $\$$ or quasi random $\$$ or pseudo-random $\$$ or pseudo random $\$$ ).tw.

50. ((multicenter or multicentre or therapeutic) adj5 (trial\$ or stud\$)).tw.

51. ((control or experiment $\$$ or conservative) adj5 (treatment or therapy or procedure or manage $\$)$ ).tw.

52. ( (singl $\$$ or doubl $\$$ or tripl $\$$ or trebl $\$$ ) adj5 (blind $\$$ or mask $\$)$ ).tw.

53. (coin adj5 (flip or flipped or toss\$)).tw.

54. latin square.tw.

55. versus.tw.

56. (cross-over or cross over or crossover).tw.

57. placebo\$.tw.

58. sham.tw.

59. (assign $\$$ or alternate or allocat $\$$ or counterbalance $\$$ or multiple baseline).tw.

60. controls.tw.

61. (treatment $\$$ adj6 order).tw.

62. or/24-61

63. 23 and 62

64. exp child/ or exp infant/

65. (neonat $\$$ or child or children or childhood or juvenile or infant or toddler).tw

66. exp neoplasms/

67. (cancer $\$$ or carcinoma $\$$ or tumor $\$$ or tumour $\$$ or neoplasm $\$$ ).tw

Interventions for disorders of eye movement in patients with stroke (Review)

Copyright @ 201 I The Cochrane Collaboration. Published by John Wiley \& Sons, Ltd. 
68. case reports.pt or case report $\$$. tw

69. 64 or 65 or 66 or 67 or 68

70. 63 not 69

71. limit 70 to humans

\section{Appendix 3. EMBASE search strategy}

1. cerebrovascular disease/ or basal ganglion hemorrhage/ or cerebral artery disease/ or cerebrovascular accident/ or stroke/ or exp carotid artery disease/ or exp brain hematoma/ or exp brain hemorrhage/ or exp brain infarction/ or exp brain ischemia/ or exp cerebrovascular malformation/ or exp intracranial aneurysm/ or exp occlusive cerebrovascular disease/ or stroke unit/ or stroke patient.mp. [mp=title, abstract, subject headings, heading word, drug trade name, original title, device manufacturer, drug manufacturer name]

2. (stroke or poststroke or post-stroke or cerebrovasc $\$$ or brain vasc $\$$ or cerebral vasc $\$$ or cva $\$$ or apoplex $\$$ or $S A H)$.tw.

3. ((brain $\$$ or cerebr $\$$ or cerebell $\$$ or intracran $\$$ or intracerebral) adj5 (isch?emi $\$$ or infarct $\$$ or thrombo $\$$ or emboli $\$$ or occlus $\$)$ ).tw.

4. ((brain $\$$ or cerebr $\$$ or cerebell\$ or intracerebral or intracranial or subarachnoid) adj5 (haemorrhage $\$$ or hemorrhage $\$$ or haematoma $\$$ or hematoma $\$$ or bleed $\$)$ ).tw.

5. hemiparesis/ or hemiplegia/ or paresis/

6. (hemipleg\$ or hemipar\$ or paresis or paretic).tw.

7. 1 or 2 or 3 or 4 or 5 or 6

8. exp eye/ or exp eye disease/ or exp visual disorder/

9. exp visual system examination/ or eye examination/ or exp vision test/

10. exp ophthalmology/ or orthoptics/ or exp visual system/ or exp visual system function/ or depth perception/

11. exp visual aid/

12. abducens nerve/ or oculomotor nerve/ or trochlear nerve/

13. (nystagmus or smooth pursuit or saccades or depth perception or stereopsis or gaze disorder\$ or retinal or retinopathy or macular degeneration or glaucoma or cataract $\$$ or ophthalmol\$ or optic nerve).tw.

14. (intranuclear ophthalmoplegia or parinaud's syndrome or weber's syndrome or skew deviation or conjugate deviation or (one adj3 half syndrome)).tw.

15. ((visual $\$$ or vision or eye or eyes or eyesight or sight) adj5 (problem\$ or disorder $\$$ or impair $\$$ or disabilit $\$$ or loss or disease $\$$ or defect $\$$ or manifestation $\$$ or screening or test $\$$ or examination $\$)$ ).tw.

16. (hemianop\$ or blindness or low vision or refractive errors or vitreoretinopathy or vitreous detachment or scotoma or diplopia or optometr\$ or ocular or orthoptic\$).tw.

17. (oscillopsia or visual tracking or fresnel prism\$).tw.

18. ((III or IV or VI or third or fourth or sixth) adj3 nerve palsy).tw.

19.8 or 9 or 10 or 11 or 12 or 13 or 14 or 15 or 16 or 17 or 18

20.7 and 19

21. Randomized Controlled Trial/

22. Randomization/

23. Controlled Study/

24. control group/

25. clinical trial/ or phase 1 clinical trial/ or phase 2 clinical trial/ or phase 3 clinical trial/ or phase 4 clinical trial/ or controlled clinical trial/

26. Crossover Procedure/

27. Double Blind Procedure/

28. Single Blind Procedure/ or triple blind procedure/

29. latin square design/

30. Parallel Design/

31. placebo/

32. Multicenter Study/

33. experimental design/ or experimental study/ or quasi experimental study/

34. experimental therapy/

35. drug comparison/ or drug dose comparison/

36. drug screening/

Interventions for disorders of eye movement in patients with stroke (Review)

Copyright @ 201 I The Cochrane Collaboration. Published by John Wiley \& Sons, Ltd. 
37. Evaluation/ or "Evaluation and Follow Up"/ or evaluation research/ or clinical evaluation/

38. Methodology/

39. "types of study"/

40. research subject/

41. Comparative Study/

42. random\$.tw.

43. (controlled adj5 (trial\$ or stud\$)).tw.

44. (clinical\$ adj5 trial\$).tw.

45. ((control or treatment or experiment\$ or intervention) adj5 (group\$ or subject\$ or patient\$)).tw.

46. (quasi-random $\$$ or quasi random $\$$ or pseudo-random $\$$ or pseudo random $\$$ ).tw.

47. ((multicenter or multicentre or therapeutic) adj5 (trial\$ or stud\$)).tw.

48. ((control or experiment $\$$ or conservative) adj5 (treatment or therapy or procedure or manage $\$)$ ).tw.

49. ((singl\$ or doubl\$ or tripl\$ or trebl\$) adj5 (blind\$ or mask\$)).tw.

50. (coin adj5 (flip or flipped or toss\$)).tw.

51. latin square.tw.

52. versus.tw.

53. (cross-over or cross over or crossover).tw.

54. placebo $\$ . t w$.

55. sham.tw.

56. (assign $\$$ or alternate or allocat $\$$ or counterbalance $\$$ or multiple baseline).tw.

57. controls.tw.

58. (treatment $\$$ adj6 order).tw.

59. or $/ 21-58$

60. 20 and 59

61. exp child/ or exp newborn/

62. (neonat $\$$ or child or children or childhood or juvenile or infant or toddler).tw.

63. exp Neoplasm/

64. (cancer $\$$ or carcinoma $\$$ or tumor\$ or tumour\$ or neoplasm $\$$ ).tw.

65. case report/ or case study/

66. 61 or 62 or 63 or 64 or 65

67. 60 not 66

68. limit 67 to human

\section{Appendix 4. CINAHL search strategy}

1. MH "Cerebrovascular Disorders+" or MH "stroke patients" or MH "stroke units"

2. TI ( stroke or poststroke or post-stroke or cerebrovasc* or brain vasc*) or AB ( stroke or poststroke or post-stroke or cerebrovasc* or brain vasc* $)$

3. TI ( brain* or cerebr* or cerebell* or intracran* or intracerebral ) or AB ( brain* or cerebr* or cerebell* or intracran* or intracerebral )

4. TI ( ischemi* or ischaemi* or infarct* or thrombo* or emboli* or occlus* ) or AB (ischemi* or ischaemi* or infarct* or thrombo* or emboli* or occlus*)

5. S3 and S4

6. TI ( brain* or cerebr* or cerebell* or intracerebral or intracranial or subarachmoid ) or AB ( brain* or cerebr* or cerebell* or intracerebral or intracranial or subarachnoid )

7. TI ( haemorrhage* or hemorrhage* or haematoma* or hematoma* or bleed*) or AB ( haemorrhage* or hemorrhage* or haematoma* or hematoma* or bleed*)

8. S6 and S7

9. $\mathrm{MH}$ "Hemiplegia"

10. TI ( hemipleg* or hemipar* or paresis or paretic ) or AB ( hemipleg* or hemipar* or paresis or paretic

11. S1 or S2 or S5 or S8 or S9 or S10

12. MH "Eye+" or MH "Rehabilitation of Vision Impaired+" or MH "Optometry" or MH "Eye Diseases+"

Interventions for disorders of eye movement in patients with stroke (Review)

Copyright $\odot 2011$ The Cochrane Collaboration. Published by John Wiley \& Sons, Ltd. 
13. MH "Visual Acuity+" or MH "Perimetry+" or MH "Ophthalmology+" or MH "Vision Screening+" or MH "Ocular Physiology+"

14. TI ( orthoptics or vision, monocular or vision, binocular) or $\mathrm{AB}$ ( orthoptics or vision, monocular or vision, binocular )

15. TI ( vitreous detachment or hemianopsia or hemianopia or quadrantanopia ) or AB ( vitreous detachment or hemianopsia or hemianopia or quadrantanopia )

16. $\mathrm{MH}$ “Abducens Nerve" or MH “oculomotor nerve" or $\mathrm{MH}$ "troclear nerve" or MH "optic nerve" or MH "nystagmus, pathologic 17. TI ( smooth pursuit or saccades or gaze disorder* or retinal or retinopathy or ophthalmol*) or AB ( smooth pursuit or saccades or gaze disorder* or retinal or retinopathy or ophthalmol*)

18. TI ( hemianop* or blindness or low vision or refractive errors or vitreoretinopathy or vitreous detachment or scotoma or diplopia or optometry* or ocular or orthoptic*) or $\mathrm{AB}$ ( hemianop* or blindness or low vision or refractive errors or vitreoretinopathy or vitreous detachment or scotoma or diplopia or optometry* or ocular or orthoptic*)

19. TI ( oscillopsia or visual tracking or fresnel prism*) or AB (oscillopsia or visual tracking or fresnel prism*)

20. TI ( intranuclear ophthalmoplegia or parinaud's syndrome or weber's syndrome or skew deviation or conjugate deviation ) or AB ( intranuclear ophthalmoplegia or parinaud's syndrome or weber's syndrome or skew deviation or conjugate deviation )

21. TI ( visual* or vision or eye or eyes or eyesight or sight ) or AB ( visual* or vision or eye or eyes or eyesight or sight )

22. TI ( problem* ${ }^{*}$ or disorder* or impair* or disability* or loss or disease* or defect* or manifestation* ${ }^{*}$ or screening or test* or examination* ) or AB ( problem* or disorder* or impair* or disability* or loss or disease* or defect* or manifestation* or screening or test* or examination*)

23. 21 and S22

24. TI ( third or fourth or sixth ) or AB ( third or fourth or sixth )

25. AB nerve palsy or TI nerve palsy

26. S24 and S25

27. S12 or S13 or S14 or S15 or S16 or S17 or S18 or S19 or S20 or S23 or S26

28. $\mathrm{S} 11$ and $\mathrm{S} 27$

29. (MH "Random Assignment") or (MH "Random Sample+")

30. (MH "Crossover Design") or (MH "Clinical Trials+") or (MH "Comparative Studies")

31. (MH "Control (Research)") or (MH "Control Group")

32. (MH "Factorial Design") or (MH "Quasi-Experimental Studies") or (MH "Nonrandomized Trials")

33. (MH "Placebo Effect") or (MH "Placebos") or (MH "Meta Analysis")

34. (MH "Community Trials") or (MH "Experimental Studies") or (MH "One-Shot Case Study") or (MH "Pretest-Posttest Design+") or (MH "Solomon Four-Group Design") or (MH ”Static Group Comparison")

or (MH "Study Design")

35. (MH "Clinical Research") or (MH "Clinical Nursing Research")

36. PT clinical trial

37. PT systematic review

38. TI random* or $\mathrm{AB}$ random*

39. TI ( singl* or doubl* or tripl* or trebl* ) or AB ( singl* or doubl* or tripl* or trebl*)

40. TI ( blind* or mask* ${ }^{*}$ or $\mathrm{AB}$ ( blind* or mask*)

41. S39 and $S 40$

42. TI ( crossover or cross-over or placebo* or control* or factorial or sham ) or AB ( crossover or cross-over or placebo* or control* or factorial or sham )

43. TI ( clin* or intervention* or compar* or experiment* or preventive or therapeutic) or AB ( clin* or intervention* or compar* ${ }^{*}$ experiment* or preventive or therapeutic )

44. TI trial* or $\mathrm{AB}$ trial$^{*}$

45. $S 43$ and S44

46. TI ( counterbalance* or multiple baseline* or $\mathrm{ABAB}$ design ) or $\mathrm{AB}$ ( counterbalance* or multiple baseline* or $\mathrm{ABAB}$ design )

47. TI ( meta analysis* or metaanlaysis or meta-anlaysis or systematic review*) or AB ( meta analysis* or metaanlaysis or meta-anlaysis or systematic review*)

48. S29 or S30 or S31 or S32 or S33 or S34 or S35 or S36 or S37 or S38 or S41 or S42 or S45 or S46 or S47

Interventions for disorders of eye movement in patients with stroke (Review) 


\section{Appendix 5. AMED search strategy}

1. cerebrovascular disorders/ or exp basal ganglia cerebrovascular disease/ or exp brain ischemia/ or exp carotid artery diseases/ or exp intracranial arterial diseases/ or exp intracranial arteriovenous malformations/ or exp "intracranial embolism and thrombosis"/ or exp intracranial hemorrhages/ or stroke/ or exp brain infarction/ or vasospasm, intracranial/ or vertebral artery dissection/

2. (stroke or poststroke or post-stroke or cerebrovasc $\$$ or brain vasc $\$$ or cerebral vasc $\$$ or cva $\$$ or apoplex $\$$ or SAH).tw.

3. ((brain $\$$ or cerebr $\$$ or cerebell\$ or intracran $\$$ or intracerebral) adj5 (isch?emi $\$$ or infarct $\$$ or thrombo $\$$ or emboli $\$$ or occlus $\$)$ ).tw.

4. ((brain $\$$ or cerebr $\$$ or cerebell $\$$ or intracerebral or intracranial or subarachnoid) adj5 (haemorrhage $\$$ or hemorrhage $\$$ or haematoma $\$$ or hematoma $\$$ or bleed\$)).tw.

5. hemiplegia/ or exp paresis/

6. (hemipleg $\$$ or hemipar $\$$ or paresis or paretic).tw.

7. 1 or 2 or 3 or 4 or 5 or 6

8. exp eye/

9. exp visually impaired persons/

10. exp ocular physiological processes/ or exp diagnostic techniques, ophthalmological/

11. Optometry/ or Orthoptics/

12. eye diseases/ or vision disorders/ or eye manifestations/ or blindness/ or diplopia/

13. vision, binocular/ or vision, monocular/ or exp visual acuity/ or visual fields/ or vision, low/ or perimetry/ or ophthalmology/or vision screening/

14. exp eye diseases, hereditary/ or exp eye hemorrhage/ or exp lacrimal apparatus diseases/ or exp lens diseases/ or exp ocular hypertension/ or exp ocular hypotension/ or exp ocular motility disorders/ or exp optic nerve diseases/ or exp orbital diseases/ or exp pupil disorders/ or exp refractive errors/or exp retinal diseases/or exp blindness, cortical/or exp hemianopsia/ or exp vitreoretinopathy, proliferative/ or exp vitreous detachment/ or scotoma/

15. abducens nerve/ or oculomotor nerve/ or trochlear nerve/

16. (nystagmus or smooth pursuit or saccades or depth perception or stereopsis or gaze disorder $\$$ or retinal or retinopathy or macular degeneration or glaucoma or cataract $\$$ or ophthalmol $\$$ or optic nerve).tw.

17. (intranuclear ophthalmoplegia or parinaud's syndrome or weber's syndrome or skew deviation or conjugate deviation or (one adj3 half syndrome)).tw

18. ((visual $\$$ or vision or eye or eyes or eyesight or sight) adj5 (problem $\$$ or disorder $\$$ or impair $\$$ or disabilit $\$$ or loss or disease $\$$ or defect $\$$ or manifestation $\$$ or screening or test $\$$ or examination $\$)$ ).tw.

19. (hemianop\$ or blindness or low vision or refractive errors or vitreoretinopathy or vitreous detachment or scotoma or diplopia or optometr\$ or ocular or orthoptic $\$)$.tw.

20. (oscillopsia or visual tracking or fresnel prism\$).tw

21. ((III or IV or VI or third or fourth or sixth) adj3 nerve palsy).tw

22.8 or 9 or 10 or 11 or 12 or 13 or 14 or 15 or 16 or 17 or 18 or 19 or 20 or 21

23.7 and 22

24. Randomized Controlled Trials as Topic/

25. random allocation/

26. Controlled Clinical Trials as Topic/

27. control groups/

28. clinical trials as topic/ or clinical trials, phase i as topic/ or clinical trials, phase ii as topic/ or clinical trials, phase iii as topic/ or clinical trials, phase iv as topic/

29. double-blind method/

30. single-blind method/

31. Placebos/

32. placebo effect/

33. cross-over studies/

34. Multicenter Studies as Topic/

35. Therapies, Investigational/

36. Drug Evaluation/

37. Research Design/

38. Program Evaluation/

39. evaluation studies as topic/

Interventions for disorders of eye movement in patients with stroke (Review)

Copyright @ 201 I The Cochrane Collaboration. Published by John Wiley \& Sons, Ltd. 
40. randomized controlled trial.pt.

41. controlled clinical trial.pt.

42. (clinical trial or clinical trial phase i or clinical trial phase ii or clinical trial phase iii or clinical trial phase iv).pt.

43. multicenter study.pt.

44. (evaluation studies or comparative study).pt.

45. random\$.tw.

46. (controlled adj5 (trial\$ or stud\$)).tw.

47. (clinical\$ adj5 trial\$).tw.

48. ((control or treatment or experiment\$ or intervention) adj5 (group\$ or subject\$ or patient\$)).tw.

49. (quasi-random $\$$ or quasi random $\$$ or pseudo-random $\$$ or pseudo random $\$$ ).tw.

50. ((multicenter or multicentre or therapeutic) adj5 (trial\$ or stud\$)).tw.

51. ((control or experiment $\$$ or conservative) adj5 (treatment or therapy or procedure or manage $\$)$ ).tw.

52. ( (singl $\$$ or doubl $\$$ or tripl $\$$ or trebl $\$$ ) adj5 (blind $\$$ or mask $\$)$ ).tw.

53. (coin adj5 (flip or flipped or toss\$)).tw.

54. latin square.tw.

55. versus.tw.

56. (cross-over or cross over or crossover).tw.

57. placebo $\$ . t w$.

58. sham.tw.

59. (assign $\$$ or alternate or allocat $\$$ or counterbalance $\$$ or multiple baseline).tw.

60. controls.tw.

61. (treatment $\$$ adj6 order).tw.

62. or/24-61

63. 23 and 62

64. exp child/ or exp infant/

65. (neonat\$ or child or children or childhood or juvenile or infant or toddler).tw

66. exp neoplasms/

67. (cancer $\$$ or carcinoma $\$$ or tumor $\$$ or tumour $\$$ or neoplasm $\$$ ).tw

68. case reports.pt or case report $\$ . \mathrm{tw}$

69. 64 or 65 or 66 or 67 or 68

70.63 not 69

71. limit 70 to humans

\section{Appendix 6. PsycINFO search strategy}

1. cerebrovascular disorders/ or exp basal ganglia cerebrovascular disease/ or exp brain ischemia/ or exp carotid artery diseases/ or exp intracranial arterial diseases/ or exp intracranial arteriovenous malformations/ or exp "intracranial embolism and thrombosis“/ or exp intracranial hemorrhages/ or stroke/ or exp brain infarction/ or vasospasm, intracranial/ or vertebral artery dissection/

2. (stroke or poststroke or post-stroke or cerebrovasc $\$$ or brain vasc $\$$ or cerebral vasc $\$$ or cva $\$$ or apoplex $\$$ or $S A H)$.tw.

3. ((brain $\$$ or cerebr $\$$ or cerebell $\$$ or intracran $\$$ or intracerebral) adj5 (isch?emi $\$$ or infarct $\$$ or thrombo $\$$ or emboli $\$$ or occlus $\$)$ ).tw.

4. ((brain $\$$ or cerebr $\$$ or cerebell $\$$ or intracerebral or intracranial or subarachnoid) adj5 (haemorrhage $\$$ or hemorrhage $\$$ or haematoma $\$$ or hematoma $\$$ or bleed $\$)$ ).tw.

5. hemiplegia/ or exp paresis/

6. (hemipleg\$ or hemipar\$ or paresis or paretic).tw.

7. 1 or 2 or 3 or 4 or 5 or 6

8. exp eye/

9. exp visually impaired persons/

10. exp ocular physiological processes/ or exp diagnostic techniques, ophthalmological/

11. Optometry/ or Orthoptics/

12. eye diseases/ or vision disorders/ or eye manifestations/ or blindness/or diplopia/

13. vision, binocular/ or vision, monocular/ or exp visual acuity/ or visual fields/ or vision, low/ or perimetry/ or ophthalmology/ or vision screening/

Interventions for disorders of eye movement in patients with stroke (Review)

Copyright @ 201 I The Cochrane Collaboration. Published by John Wiley \& Sons, Ltd. 
14. exp eye diseases, hereditary/ or exp eye hemorrhage/ or exp lacrimal apparatus diseases/ or exp lens diseases/ or exp ocular hypertension/ or exp ocular hypotension/ or exp ocular motility disorders/ or exp optic nerve diseases/ or exp orbital diseases/ or exp pupil disorders/ or exp refractive errors/or exp retinal diseases/ or exp blindness, cortical/or exp hemianopsia/ or exp vitreoretinopathy, proliferative/ or exp vitreous detachment/ or scotoma/

15. abducens nerve/ or oculomotor nerve/ or trochlear nerve/

16. (nystagmus or smooth pursuit or saccades or depth perception or stereopsis or gaze disorder\$ or retinal or retinopathy or macular degeneration or glaucoma or cataract $\$$ or ophthalmol $\$$ or optic nerve).tw.

17. (intranuclear ophthalmoplegia or parinaud's syndrome or weber's syndrome or skew deviation or conjugate deviation or (one adj3 half syndrome)).tw

18. ((visual\$ or vision or eye or eyes or eyesight or sight) adj5 (problem $\$$ or disorder $\$$ or impair $\$$ or disabilit $\$$ or loss or disease $\$$ or defect $\$$ or manifestation $\$$ or screening or test $\$$ or examination $\$)$ ).tw.

19. (hemianop $\$$ or blindness or low vision or refractive errors or vitreoretinopathy or vitreous detachment or scotoma or diplopia or optometr\$ or ocular or orthoptic\$).tw.

20. (oscillopsia or visual tracking or fresnel prism\$).tw

21. ((III or IV or VI or third or fourth or sixth) adj3 nerve palsy).tw

22. 8 or 9 or 10 or 11 or 12 or 13 or 14 or 15 or 16 or 17 or 18 or 19 or 20 or 21

23.7 and 22

24. Randomized Controlled Trials as Topic/

25. random allocation/

26. Controlled Clinical Trials as Topic/

27. control groups/

28. clinical trials as topic/ or clinical trials, phase i as topic/ or clinical trials, phase ii as topic/ or clinical trials, phase iii as topic/ or clinical trials, phase iv as topic/

29. double-blind method/

30. single-blind method/

31. Placebos/

32. placebo effect/

33. cross-over studies/

34. Multicenter Studies as Topic/

35. Therapies, Investigational/

36. Drug Evaluation/

37. Research Design/

38. Program Evaluation/

39. evaluation studies as topic/

40. randomized controlled trial.pt.

41. controlled clinical trial.pt.

42. (clinical trial or clinical trial phase i or clinical trial phase ii or clinical trial phase iii or clinical trial phase iv).pt.

43. multicenter study.pt.

44. (evaluation studies or comparative study).pt.

45. random\$.tw.

46. (controlled adj5 (trial\$ or stud\$)).tw.

47. (clinical\$ adj5 trial\$).tw.

48. ((control or treatment or experiment\$ or intervention) adj5 (group\$ or subject\$ or patient\$)).tw.

49. (quasi-random $\$$ or quasi random $\$$ or pseudo-random $\$$ or pseudo random $\$$ ).tw.

50. ((multicenter or multicentre or therapeutic) adj5 (trial\$ or stud\$)).tw.

51. ((control or experiment $\$$ or conservative) adj5 (treatment or therapy or procedure or manage $\$)$ ).tw.

52. ( (singl\$ or doubl\$ or tripl\$ or trebl\$) adj5 (blind $\$$ or mask $\$)$ ).tw.

53. (coin adj5 (flip or flipped or toss\$)).tw.

54. latin square.tw.

55. versus.tw.

56. (cross-over or cross over or crossover).tw.

57. placebo $\$ . t w$.

58. sham.tw.

Interventions for disorders of eye movement in patients with stroke (Review)

Copyright $\odot 201$ I The Cochrane Collaboration. Published by John Wiley \& Sons, Ltd. 
59. (assign $\$$ or alternate or allocat $\$$ or counterbalance $\$$ or multiple baseline).tw.

60. controls.tw.

61. (treatment $\$$ adj6 order).tw.

62. or/24-61

63. 23 and 62

64. exp child/ or exp infant/

65. (neonat $\$$ or child or children or childhood or juvenile or infant or toddler).tw

66. exp neoplasms/

67. (cancer\$ or carcinoma $\$$ or tumor $\$$ or tumour $\$$ or neoplasm $\$$ ).tw

68. case reports.pt or case report $\$$.tw

69.64 or 65 or 66 or 67 or 68

70.63 not 69

71. limit 70 to humans

\section{CONTRIBUTIONS OFAUTHORS}

Alex Pollock led this review, provided methodological expertise, acted as a second reviewer, and co-wrote the final drafts. Christine Hazelton ran searches, identified relevant studies, acted as first reviewer, provided content expertise and co-wrote the final drafts. Fiona Rowe, Baljean Dhillon, Heather Orr, Katrina Livingstone, Frank A Munro, Uma Shahani, Jayne Angilley, Clair Henderson and Peter Langhorne provided additional content expertise, read and commented on final drafts, and acted as additional reviewers where there was uncertainty or disagreement.

\section{DECLARATIONSOF INTEREST}

Alex Pollock has received funding from the Royal National Institute for Blind People (RNIB) to support research relating to visual problems after stroke (including this Cochrane review). This funding supports the salary of a research assistant on this review. Christine Hazelton's post as research assistant on this review is funded by RNIB. Clair Henderson works for RNIB, which is the leading organisation in the UK supporting blind and partially-sighted people. The work presented here represents the views of the review authors and not necessarily those of the funding bodies.

\section{SOURCES OF SUPPORT}

\section{Internal sources}

- No sources of support supplied

\section{External sources}

- Royal National Institute of Blind People (RNIB, Scotland), UK.

RNIB (Scotland) have funded this Review, and employ Clair Henderson.

- Chief Scientist Office, Scottish Government, UK.

Alex Pollock is employed by the Nursing, Midwifery and Allied Health Professions Research Unit, which is funded by the Chief Scientist Office in Scotland.

Interventions for disorders of eye movement in patients with stroke (Review) 


\section{DIFFERENCES BETWEEN PROTOCOLANDREVIEW}

In the protocol we stated that we planned to classify interventions as either restitution, compensation, substitution, or assessment and screening. We were unable to reach agreement on the classification of the included studies and in the review we introduced a new classification of pharmacological interventions.

\section{INDEX TERMS}

\section{Medical Subject Headings (MeSH)}

Activities of Daily Living; Muscarinic Antagonists [therapeutic use]; Ocular Motility Disorders [*drug therapy; etiology]; Randomized Controlled Trials as Topic; Stroke [* ${ }^{*}$ complications]; Trihexyphenidyl [therapeutic use]

\section{MeSH check words}

Adult; Humans 